\title{
THE EFFECTS OF PRICE CHANGES ON ALCOHOL CONSUMPTION IN ALCOHOL-EXPERIENCED RATS
}

Jeffrey K. Sarbaum

Solomon W. Polachek

Norman E. Spear

Working Paper 6443 
NBER WORKING PAPER SERIES

\title{
THE EFFECTS OF PRICE CHANGES ON ALCOHOL CONSUMPTION IN ALCOHOL-EXPERIENCED RATS
}

\author{
Jeffrey K. Sarbaum \\ Solomon W. Polachek \\ Norman E. Spear
}

\author{
Working Paper 6443 \\ http://www.nber.org/papers/w6443
NATIONAL BUREAU OF ECONOMIC RESEARCH
1050 Massachusetts Avenue
Cambridge, MA 02138
March 1998

This paper was presented at the National Bureau of Economic Research conference on The Economic Analysis of Substance Use and Abuse: An Integration of Econometric and Behavioral Economic Research, Cambridge, MA, March 27-28, 1997. We wish to thank Thomas Babor, Warren Bickel, Michael Grossman, Michael Hilton, Clifford Kern, and John Robst for valuable comments and suggestions. Any opinions expressed are those of the authors and not those of the National Bureau of Economic Research.

(C) 1998 by Jeffrey K. Sarbaum, Solomon Polachek, Norman E. Spear. All rights reserved. Short sections of text, not to exceed two paragraphs, may be quoted without explicit permission provided that full credit, including (C) notice, is given to the source. 
The Effects of Price Changes on Alcohol Consumption

in Alcohol-Experienced Rats

Jeffrey K. Sarbaum, Solomon W. Polachek

and Norman E. Spear

NBER Working Paper No. 6443

March 1998

\section{$\underline{\text { ABSTRACT }}$}

This paper reports results of two experiments designed to measure how addicted rats (i.e. laboratory rats with previous ethanol exposure via a variant of the Samson ethanol fading technique) respond to changes in the price of ethanol. For both experiments, rats facing a budget constraint choose between two alternative non-ethanol commodities in a morning control session and between ethanol and a non-ethanol commodity in an afternoon session. The results from both experiments shows that economic models of consumer choice are a useful tool to study ethanol and non-ethanol consumption in rats, and that a history of ethanol exposure did not interfere with rats' ability to behave according to economic theory. In the first experiment, rats responded only moderately to a $100 \%$ price increase (especially when compared to the response for the non-ethanol commodity during the control session), but more dramatically for a $400 \%$ ethanol price increase. However, going back to baseline prices after a prolonged duration of high ethanol prices yields some evidence that ethanol consumption declines below its original levels. In the second experiment rats responded to increased ethanol prices but not to a cue signaling future price increases. Thus, the experiments provide evidence supporting habit formation but not rational addiction as an explanation of ethanol consumption in rats.

Jeffrey K. Sarbaum

Department of Economics

Willamette University

Salem, OR 97301

Norman E. Spear

Department of Psychology

State University of New York

Binghamton, NY 13902
Solomon W. Polachek

Dean, Harper College

State University of New York

Binghamton, NY 13902 


\section{Introduction}

This paper reports the results of two experiments designed to study ethanol consumption. The innovation is to analyze the behavior of ethanol-experienced rats as opposed to humans as done in current economics based studies. The reason for using animal subjects is interesting, but first we give some background.

Current economic studies view alcohol as an addictive commodity. Addictive commodities are ones which have repercussions on future consumption. As such, consuming this type commodity affects one's benefit from consuming this commodity some time in the future. Addiction thus implies a time complementarity which enables economists to derive predictable theorems regarding intertemporal consumption patterns. For example, under plausible assumptions two theorems emerge: First, long nun responses to a price change are relatively larger than short-run responses for addictive compared to nonaddictive commodities (Becker, Grossman, and Murphy, 1991). And second, past as well as future prices affect consumption behavior rather than simply current prices as is typical for non-addictive commodities (Becker and Murphy, 1988).

Empirical studies validate these theorems essentially by regressing current consumption on past, present and future prices. Current studies (Chaloupka, 1991; Becker, Grossman, and Murphy, 1994; Grossman, Chaloupka, and Sirtalan, 1995; Grossman, Chaloupka, and Brown, 1996) analyze the demand for cigarettes, alcohol, and cocaine. Aggregate data analysis examines cross-sectional state data by making use of interstate variations in prices. Studies (Grossman, Chaloupka, and Sirtalan, 1995; Grossman, Chaloupka, and Brown, 1996) utilizing panel data (e.g., the University of Michigan's Institute for Social Research's Monitoring the Future panels) analyze cross-sectional as well as time-series price changes. Both type of studies find responses to price changes to be greater in the long-run, implying larger long-run elasticities. However, a deficiency with these studies is that there are numerous other explanations why long-run elasticities are larger than short-run elasticities. As such, long-run elasticities exceed short-run elasticities for many commodities, not just addictive ones. Past studies lack the data on other commodity purchases to compare differences in long-run and short-run elasticities between addictive and non- 
addictive commodities. As such one does not know whether alcohol, cigarettes and drugs have long-run elasticities that exceed short-run elasticities because common economic theory dictates this or because these commodities exhibit the time-complementarities inherent with addictive consumption. Thus a controlled experiment is needed to calibrate response differences between addictive and non-addictive commodities.

The point of this paper is not to test long run versus short run elasticities, but to perform controlled experiments to compare demand elasticities between addictive and non-addictive commodities. Only by first determining such elasticities can one begin to study relative long run and short run differences. In the first experiment ethanol experienced rats facing a fixed budget (limited number of reinforcements) choose between two alternative non-ethanol commodities in a morning control session and between an ethanol and a non-ethanol commodity in an afternoon session. Their response to an increase in the price of the ethanol commodity in this circumstance is compared against their response to an increase in the price of a non-ethanol commodity derived from a series of controls. The design enables direct comparisons to be made between the demand elasticities for the ethanol and non-ethanol commodities. We corroborate these results in a second experiment that examines price changes in an alternative setting. In this experiment we employ a mechanism to consider future price alterations as well. This additional element potentially has implications regarding the Becker-Murphy (1988) notion of rational addiction.

In carrying out these experiments we first confirm Samson's (1986) finding that rats can be induced to consume ethanol, and will do so even when faced with non-ethanol alternatives. This outcome implies that current ethanol consumption depends on past ethanol use, a test of the habit formation or addiction framework. Second, we find unambiguously that price changes affect behavior. This is true both for non-ethanol as well as ethanol commodities, though the magnitudes differ for each. Third, we find that in general ethanol experienced rats respond less to ethanol price changes than to otherwise identical nonethanol price changes. Fourth, we were unable to uncover evidence that future price changes affect ethanol consumption. Although tentative, these results confirm the value of utilizing the price structure to affect behavior, even for addictive commodities. 


\section{The Becker-Murphy model of rational addiction: An intuitive explanation}

The Becker-Murphy theory (1988) treats addiction as a rational behavior, where rationality implies that individuals gauge consumption via prudent behavior over their lifetime (lifecycle utility maximization). Addictive consumption is distinguished from other consumption by assuming that past consumption enhances current consumption (thus an addictive good is a compliment to itself over time, or a time compliment). As a result, consumption of an addictive good in one period affects the decision to consume that good in future periods -- a condition which must be accounted for in lifecycle utility maximization.

Current consumption of an addictive good can affect future consumption in two ways. First, current consumption can increase the benefit (marginal utility) of future consumption, implying that current consumption "reinforces" future consumption. Second, current consumption can decrease the marginal utility of future consumption, implying that current consumption has a "tolerating" effect on future consumption. In other words, the decision to consume some quantity of an addictive good is a function of the tolerating and reinforcing effects that result from its past consumption. In addition, since time complementarity applies to both past and future periods, for a rational consumer the decision to consume an addictive good also depends on expectations about future events, such as changes in price (Becker and Murphy, 1988; Pollak, 1976).

In the Becker-Murphy model, an important determinant of the consumption of an addictive good is the reinforcing effects from its past consumption. Consequently, reinforcement plays a critical role in determining the consumption of addictive goods. For example, consider the potential role of alcohol (nicotine) to a drinker (smoker). Prior to a drinker's (smoker's) first drink (cigarette) there is no alcohol (nicotine), i.e., "alcohol (nicotine) reinforcement", in the consumer's system. Given this, the decision to drink (smoke) could not be driven by some reinforcing influence from prior alcohol (nicotine) exposure. However, numerous lifecycle events could cause a non-drinker (non-smoker) to begin drinking (smoking). Consider peer pressure and increased stress to name just two. Once the consumer began drinking (smoking), its reinforcing effects would make future alcohol (nicotine) consumption more desirable. The influence of past consumption on current consumption is regulated by two things; additional drinking 
(smoking) which would increase it, and depreciation which would decrease it. Depreciation can essentially be viewed as the decline in the reinforcing efficacy of past consumption on current consumption over time. Eventually, a utility maximizing "addicted" drinker (smoker) should reach a predictable consumption pattern, where the influences of past consumption remained constant over time In other words, each period the gain in the reinforcement from additional drinking (smoking) would just offset the loss in reinforcement resulting from depreciation.

The consumption patterns for addictive goods tend to be unstable, however, particularly when their reinforcing effects are strongest. Changes in consumption in one period tend to result in larger effects over time (in the long run). The reason for this is simple. Deviations from stable consumption patterns affect levels of reinforcement, which subsequently influence future consumption decisions. For example, if consumption rose today it would make the addictive good more appealing tomorrow (through time complimentarity). As a result, tomorrow's consumption would increase, giving further stimulation to the next day's consumption and so on. Consumption would continue to increase until a new, stable, pattern was established.

Viewing addictive goods as ones that enhance their own consumption (time compliments) helps to explain why, for example, a social drinker might go on to become an alcoholic after a stressful event caused their initial social drinking to increase by only a few drinks. It might also help to explain the consumption patterns of new "casual" cigarette smokers. Very few "casual" smokers remain so. Most either quit or go on to become heavy smokers. This suggests that stable consumption patterns for highly addictive goods, like cigarettes, tend to only exist at the extremes - abstinence or excess.

It is important to recognize that addiction is caused by the interaction of a good and consumer. Some consumers will find potentially addictive goods highly reinforcing while others may find them much less so, perhaps due to life cycle events and psychological or physiological design. This interaction is critical because it helps to explain why, for example, two people with similar lifecycle experiences who begin drinking (smoking) may have different consumption experiences. One may go on to become an alcoholic (chain smoker) while the other may not. Similar stories could be told for other potentially addictive goods, such as cocaine, heroin and marijuana. 
One event which can cause consumption to deviate from a consistent pattern is a change in price. Intuition would seem to imply that price changes have very little effect on the consumption of addictive goods, particularly in the short run. However, as stated above, the reinforcing effects from even a small change can have a profound impact on future consumption decisions. For example, a decrease in price would lead to increased consumption, and through time complimentarity make future consumption more reinforcing. As such, future consumption would increase further resulting in a larger long run response to the price change ( larger long run elasticity). Through symmetry, the opposite would hold for an increase in price. In general, consumers of addictive goods become increasingly responsive to initial changes in price and other events which cause consumption to change.

The degree of addiction influences the relationship between short run and long run price effects. By definition, when the degree of addiction is highest, the level of reinforcement is strongest. This implies that small deviations from stable consumption patterns will have larger long run effects the greater the level of addiction. Consumers with strong addictions are more responsive to a price change over time than consumers who are less addicted - implying that long run price elasticities are largest when the degree of addiction is strongest (Becker, Grossman, and Murphy, 1991).

A rational consumer will take into account not only past behavior but also expectations of future behavior when maximizing lifetime utility. Through time complimentarity, future considerations will necessarily affect the current consumption of addictive goods. For example, if a tax on alcohol (cigarettes) passed legislation and is expected to take effect next year, a rational consumer would reduce current consumption in order to rectuce the reinforcing effect of alcohol (nicotine) in the future. As a result, the consumer would be more easily able to respond the higher future price, substituting away from alcohol (cigarettes) and using the money to purchase some other, relatively cheaper, reinforcing commodity.

\section{An experimental model of consumer choice using laboratory animals}

Models of consumer choice study how consumers respond to changes in the relative price of commodities when facing a budget or income constraint. Downward sloping demand curves imply that, other things being equal, the quantity demanded of a commodity will fall as the relative price of that 
commodity increases. The downwardly sloped demand curves are based on the assumption that consumers maximize satisfaction, a function of the commodities they consume, subject to a budget constraint.

To model these circumstances rats in an experimental testing chamber were given a budget to allocate between two alternative commodities, $\mathrm{X}$ and $\mathrm{Y}$. The operant chamber was equipped with two levers, each of which delivered a reinforcing liquid commodity when pressed. The budget was set by limiting the number of lever presses available to the subject in a given test session. The price of each commodity was determined by the number of lever presses required to obtain $0.1 \mathrm{ml}$ of liquid commodity from the associated dispenser. Relative prices were determined by the price ratio $\left(\mathrm{P}_{\mathrm{X}} / \mathrm{P}_{\mathrm{Y}}\right)$ of the two alternative commodities. Income was determined by a fixed number of available lever presses. Responsiveness to a change in price was measured by the price elasticity of demand If the price of a commodity rises by a larger percentage than the percent fall in quantity demanded, then the commodity is considered to be price inelastic. If price rises by a smaller percentage than the percent fall in quantity, then the commodity is considered to be price elastic. Price elasticity of demand is measured by fitting a $\log$ linear function to the price-consumption data recorded during the experiments:

$$
\log Q \mathbf{x}=\log \alpha_{0}+\alpha_{1} \log (\mathbf{P x} / \mathbf{P y})
$$

where $\alpha_{1}$ measures the price elasticity of demand. In the context of these experiments, the price elasticity of demand can be viewed as a measure of the degree to which a subject is willing to substitute one commodity for the other when the price, measured in terms of the forgone opportunity to consume the alternative commodity, changes.

\section{Experimental testing apparatus}

Subjects were tested in a custom operant chamber measuring $30 \mathrm{~cm}$. long, $35 \mathrm{~cm}$. wide, and 28 $\mathrm{cm}$. high (San Diego Instruments). Two metal levers projected into one wall of the chamber. Flavored sucrose and sucrose/ethanol solutions were delivered from two separate liquid dripper mechanisms located to the side of each lever. Depression of a lever resulted in a calibrated drop of the solution from the 
dripper onto a drinking tray recessed in a hole on the panel next to each lever. Drop sizes were adjustable, ranging in size from $0.025 \mathrm{ml}$ to $0.2 \mathrm{ml}$. Computer-based programming equipment controlled the number of lever presses available for operating the dispensers each session. Two white lights, one over each lever, were illuminated whenever liquid dispensing lever presses were available. When a subject exhausted its budgeted lever presses the white lever lights went off. A single 7.5 watt green light and an $80 \mathrm{db}$ Sonalert, located between the levers, were activated for signaling purposes during experiment $\# 2$. The entire operant chamber was housed in a sound proof chamber equipped with an exhaust fan. A single 7.5 watt white house light, located on the roof of the sound proof box above the operant chamber, remained on throughout the session. The programming equipment automatically recorded the number of depressions made on each lever, the time into the session each lever press was made and the time required to exhaust the budgeted number of lever presses.

\section{Experiment \#1A}

\section{Methods}

\section{Subjects}

Six adult male, 60-80 day old Sprague-Dawley rats from our laboratory's breecting facility (rats $1.1,1.2,1.3,1.4,1 . \mathrm{Cl}$ and 1.C2) were singly housed in standard hanging cages in a temperature and light controlled colony room. Subjects had ad lib. access to water and standard laboratory rat chow while in their home cage. Subjects 1.1, 1.2, 1.3 and 1.4 were exposed to a variant of the Samson sucrose-ethanol fading technique in their home cage prior to testing in an experimental chamber (Samson, 1986), as detailed in the experimental design subsection. Subjects 1.C1 and 1.C2 were ethanol naive rats and served as controls during the experimental testing.

\section{Experimental design}

Table 1 shows the baseline and experimental parameters (solution flavors, budgets and drop sizes per lever press) for each subject as well as the mean lever presses, solution intake levels, intake standard deviations and ethanol intake $(\mathrm{g} / \mathrm{kg})$ under each condition.

Modified Samson (1986) ethanol sucrose fade. On test days 1-34 subjects $1.1,1.2,1.3$, and 1.4 were trained to drink ETOH/sucrose solutions in their home cage during daily $30 \mathrm{~min}$. drinking sessions. 
On test days $35-49$ subjects $1.1,1.2,1.3$ received concurrent $30 \mathrm{~min}$. access to two alternative flavored (. $2 \mathrm{~g} \mathrm{Kool-Aid)} \mathrm{solutions} \mathrm{in} \mathrm{their} \mathrm{home} \mathrm{cage.} \mathrm{Subjects} 1.1$ and 1.3 received a $10 \%$ sucrose $/ 15 \%$ ETOH/strawberry solution versus a $10 \%$ sucrose/orange solution. Subject 1.2 received a $10 \%$ sucrose/15\% ETOH/cherry solution versus a $10 \%$ sucrose/grape solution. On four of the concurrent home cage exposure days (test days 40 - 43) subjects were exposed to $2 \mathrm{ml}$ each of two different alternative flavor sucrose solutions 2 hours prior to the ethanol exposure. The purpose of this exposure was to determine whether access to $4 \mathrm{ml}$ of $10 \%$ flavored sucrose earlier in the day affected total and relative intake of the solutions described above. Subject 1.4 served as a control and was maintained on the $5 \%$ sucrose $15 \%$ ETOH solution according to Table 1 until test day 50.

Operant shaping On test days $50-52$, subjects $1.1,1.2$ and 1.3 were water deprived overnight and trained to lever press for water in the operant chamber using standard shaping procedures. Following each operant training session, subjects were returned to their home cage and given 1 hour access to water followed by $30 \mathrm{~min}$. access to their two respective flavored solutions. Beginning on day 53, subjects 1.1, 1.2 and 1.3 received two daily $30 \mathrm{~min}$. operant sessions, an early session between $1-2$ p.m. and a late session between 3 - 4 p.m. In the early session one of two alternative $10 \%$ sucrose/Kool-Aid flavors was delivered contingent upon a press on the respective lever (FR-1, $0.05 \mathrm{ml}$ for both levers) and in the late session a $10 \%$ sucrose/Kool-Aid flavor was associated with one lever and a $10 \%$ sucrose/ $15 \%$

ETOH/alternative Kool-Aid flavor was associated with the other (FR-1, $0.05 \mathrm{ml}$ on both levers). Table 1 shows the specific flavors associated with each lever for each session and subject.

Initiation of the budget constraint (the baseline parameters). Following the establishment of steady responding during the two daily $30 \mathrm{~min}$. sessions (test day 54 - 56 depending on the subject), a budget of 80 lever presses per each daily session was initiated - - allowing for a total intake of $4 \mathrm{ml}$ each session. Each time a subject exhausted its 80 lever press budget, or failed to exhaust its budget within a 45 min. maximum session length, it was removed from the operant chamber and returned to its home cage. Under baseline conditions, subjects were run for approximately 30 days on the 80 press, FR-1, 0.05 $\mathrm{ml} /$ press/lever schedule. Table 1 shows the specific number of days each subject was tested under baseline. 
Initiation of a $100 \%$ price change (the experimental parameters). Following the baseline period, the relative cost or price of the alternative solutions was altered by changing the drop size per lever press. For subjects 1.2 and 1.3, the drop size per lever press on one of the two levers was increased to $0.1 \mathrm{ml}$ during both daily sessions. This change doubled the relative cost of choosing the lever that provided a $0.05 \mathrm{ml}$ drop of solution and halved the relative cost of choosing the lever that provided a $0.1 \mathrm{ml}$ drop of solution. For subject 1.1, the drop size per lever press on one of the two levers was decreased to $0.025 \mathrm{ml}$ during both daily sessions causing a relative price change similar to subjects 1.2 and 1.3. For all subjects, the relative price of ethanol (in the later session) was increased. The change in relative drop sizes was accompanied by a change in allotted budgets for each subject in order to hold baseline income constant. For subjects 1.2 and 1.3 (subject 1.1) the price change was accompanied by a decrease (increase) in the budget in order to compensate for the larger (smaller) drop size per lever press available under the experimental condition. The budget adjustments allowed each subject the opportunity to consume, on average, exactly what it consumed under the baseline condition for each daily session. In general, subjects were run for approximately 30 days under experimental conditions.

Control conditions. To determine if prior ethanol exposure via the Samson fading technique was responsible for the ethanol consumption in the home cage choice environment, subject 1.C2, an ethanol naive animal, was tested under similar conditions. Subject $1 . \mathrm{C} 2$ was given daily concurrent $30 \mathrm{~min}$. access to two alternative $10 \%$ sucrose/Kool-Aid flavors for 5 days and then given similar access to the same solutions, except that $15 \%$ ethanol was added into one of the two solutions for the following 5 days.

This study was designed so that for most purposes, each subject could serve as its own control. Under the design, the behavior resulting from an increase in the price of ethanol during the late session could be compared directly to the behavior resulting from an increase in the price of an otherwise similar non-ethanol commodity during the early session. Two complications arose from this type of control. First, the effect of the earlier daily session could have influenced behavior during the late session - - although this was not found to be the case in the context of the home cage exposure. Second, the difference in the time of day between the two daily sessions could have differently influenced behavior during the sessions. Two control subjects, 1.4 and 1.Cl, were tested under different experimental parameters in order to 
ascertain whether the two complications had any confounding affects on the within-subjects comparison between the two daily sessions.

On test day 50 subject 1.4 received concurrent $30 \mathrm{~min}$. access to a $10 \%$ sucrose/15\% ETOH/strawberry solution and a $10 \%$ sucrose/orange solution in its home cage and was then tested similarly to subjects $1.1,1.2$ and 1.3 until the beginning of the baseline testing sessions. Under the baseline condition, subject 1.4 was tested only once daily for 15 sessions choosing between a $10 \%$ sucrose $15 \% \mathrm{ETOH} /$ strawberry flavor on one lever and an alternative $10 \%$ sucrose/orange flavor on the alternative lever (baseline: FR-1, $0.05 \mathrm{ml} /$ press, both levers). Next, a price change was introduced similar to that for subjects $1.1,1.2$ and 1.3 , and subject 1.4 was tested over 15 subsequent daily sessions (see Table 1 for details). Under this design, subject 1.4 was not tested in a session prior to the ethanol session each day, eliminating any influence an earlier session might have had and providing an estimate of this influence on the behavior of the other subjects. Following this test, subject 1.4 was tested again, at the same time of day and only once per day, choosing between alternative $10 \%$ sucrose/strawberry and $10 \%$ sucrose/orange solutions and facing a similar experimental price change. The subject was run for 10 days baseline and 10 days experimental condition (see Table 1 for details). Running the ethanol and nonethanol experiments back to back allowed a within subject comparison to be made between the two experiments. Although subject 1.4's experimental design eliminated the concern over the effect of two daily sessions and differences in time of day, it created a slight difference in this subject's age for the second test.

Subject 1.C1, an ethanol naive animal, was tested similarly to subjects $1.1,1.2$ and 1.3 except that it chose between two non-ethanol solutions in the late session. Subject $1 . \mathrm{Cl}$ allowed a within-subject comparison to be made between the effects of a similar price change in early and late sessions, in the absence of ethanol. The only differences between the sessions was the time of day and specific Kool-Aid flavors being used. Subject $1 . \mathrm{Cl}$ was tested for 10 days baseline and 12 days experimental condition (see Table 1 for details).

\section{Results}

\section{Home cage intake}


Figures 1,2 and 3 compare mean intake levels during the home cage condition to intake during each of the operant conditions; lines on each bar indicate standard deviation.

Control Subject 1.C2. During the first 5 of the 10 days of daily concurrent $30 \mathrm{~min}$. access to $10 \%$ sucrose/orange and $10 \%$ sucrose/strawberry in the home cage, subject $1 . \mathrm{C} 2$ indicated a preference for the orange flavor. Average orange intake was $6.2 \mathrm{ml}$ and average strawberry intake was $2.4 \mathrm{ml}$. During the second 5 days, $15 \%$ ethanol was added to the orange commodity. During this period, average consumption of orange dropped to less than $0.1 \mathrm{ml}$ and strawberry consumption rose to $7.4 \mathrm{ml}$. These results confirm, as expected, that a previously ethanol naive subject will not consume an ethanol sucrose commodity when an alternative non-ethanol sucrose commodity is concurrently available.

Subjects 1.1, 1.2 and 1.3. Subjects 1.1, 1.2 and 1.3 consumed both the ethanol and non-ethanol sucrose commodities when they were concurrently available in the home cage. In light of the results from subject 1.C2, these results suggest, also as expected, that prior ethanol exposure via the Samson fading technique is necessary to make subjects consume ethanol in the context of an otherwise similar nonethanol commodity. Average intake of each commodity was similar for all three subjects. Each drank more of the non-ethanol sucrose commodity than of the ethanol sucrose commodity, indicating that there was no preference for the ethanol commodity when both were freely available. Average intake over the 14 day period can be seen in the "Home Cage" bars in Figures 1-3.

\section{Home cage intake versus baseline operant intake}

Unlike the home cage environment in which subjects had unlimited access (for $30 \mathrm{~min}$.) to both commodities, in the operant chambers subjects faced a budget that limited their total intake. Under this paradigm, choosing to consume one commodity decreased the opportunity to consume the alternative commodity. The price of a commodity was determined by the exchange rate between the two commodities. During the baseline sessions, the cost of using a lever press to consume one commodity was giving up the opportunity to use the press to consume an equal amount of the alternative commodity, making the price of each commodity equal to 1 press. The total budget available to each subject was $4 \mathrm{ml}$ of liquid. Intake of the solutions was confirmed by checking the drinking troughs for unconsumed solution following each 
session. For all of the subjects during all of the sessions, unconsumed solution was never observed, suggesting that subjects drank all of the solution obtained by lever pressing.

During the baseline operant period subjects 1.1, 1.2 and 1.3 exhausted almost all of their budgeted $4 \mathrm{ml}$ of liquid on the ethanol commodity. Average daily ethanol intake was very similar for the home cage session and the baseline operant sessions, differing on average by less than $0.5 \mathrm{ml}$. On the other hand, consumption of the non-ethanol commodity fell dramatically, as would be required to maintain ethanol consumption given the limited budget of the baseline operant sessions. Intake of the non-ethanol commodity for subjects $1.1,1.2$ and 1.3 fell by $6.21 \mathrm{ml}, 3.82 \mathrm{ml}$ and $6.34 \mathrm{ml}$ respectively. The bar graphs labeled "Home Cage" and "Operant Price Etoh=1" in Figures 1, 2 and 3 illustrate the magnitude of the changes in consumption between the two conditions.

Operant intake - the effect of a $100 \%$ price increase on the consumption of an ethanol commodity versus a non-ethanol commodity

Relative price was changed between the operant baseline and experimental condition. In the earlier daily control session the price of one of the two non-ethanol commodities was doubled In the later ethanol session, the price of ethanol was doubled. Figures 4-8 show three day moving averages of the daily intake of each solution as well as total intake during the operant baseline and experimental condition. In Figures 4-8, the effect of the price change on intake can be seen by looking at the relative change in consumption across conditions - the commodity with the solid marks doubled in price during the experimental condition and the commodity with open marks was halved in price.

Subjects 1.2 and 1.3. Subjects 1.2 and 1.3 both responded to the price change in the earlier, nonethanol control sessions by increasing consumption of the cheaper commodity and recucing consumption of the more expensive commodity. Subject 1.2 's price elasticity of demand for strawberry when choosing between that and orange was $-0.96(t=-14.21)$, indicating that consumption of strawberry decreased by $0.96 \%$ for each $1.00 \%$ increase in its price. Subject 1.3 's price elasticity of demand for grape when choosing between that and cherry was $-1.38(t=-7.06)$, indicating that consumption of grape decreased by $1.38 \%$ for each $1.00 \%$ increase in its price. These results are consistent with the economic law of demand, indicating that the history of ethanol exposure did not interfere with the ability of these rats to make 
choices accordingly. Figures 5 and 6 show average daily intakes (derived from a three day moving average of the actual daily intake data) prior to and following the price change. These graphs illustrate the statistically significant change in intakes that resulted from the change in price. Table 1 reports the price elasticity of demand estimated from equation (1) for each subject. As the price of one commodity increased (filled circles or squares) both subjects substituted away from that commodity into the relatively cheaper (open circles or squares) commodity, which resulted in an increased total intake for the session.

In the later ethanol sessions, subjects 1.2 and 1.3 both initially responded to the increase in the price of ethanol by reducing its consumption. Then, over subsequent testing days, ethanol consumption rose until it stabilized near the baseline level. Relative to the elasticity of demand for the non-ethanol commodity during the control session, the elasticity of demand for the ethanol commodity was small for both subjects. Subject 1.2 's price elasticity of demand for cherry with $15 \%$ ethanol when choosing between that and grape was $-0: 10(t=-2.41)$, indicating that consumption of cherry with ethanol decreased by $0.10 \%$ for each $1.00 \%$ increase in its price. Subject 1.3 's price elasticity of demand for strawberry with $15 \%$ ethanol when choosing between that and orange was $-0.18(t=-2.89)$, indicating that consumption of strawberry with ethanol decreased by $0.18 \%$ for each $1.00 \%$ increase in its price. Figures 5 and 6 show mean daily intake (derived from a three day moving average of the actual daily intake) before and after the price change. Following the price change, the drop in consumption of ethanol indicates that the subjects reacted to the change in price initially but then increased consumption of ethanol, nearly back to the baseline level, over subsequent days. Figures 2 and 3 show bar graphs of the mean daily intake under each condition: home cage, operant with the price of ethanol equal to 1 , and operant with the price of ethanol equal to 2 .

When comparing the relative effect of the price change between the ethanol and non-ethanol sessions, consistent differences exist. In the control session both subjects switched consumption away from one sucrose flavored commodity in exchange for an alternatively flavored sucrose commodity when the price of the former increased. In the ethanol session the subjects did not, however, switch consumption away from the flavored ethanol sucrose commodity in exchange for the alternatively flavored non-ethanol 
sucrose commodity when the price of the ethanol commodity increased. This suggests that ethanol is very reinforcing relative to the alternative reinforcer.

Previous studies of demand using an economic model of consumer choice in rats have employed the ABA design (baseline experiment - baseline) used in the present study. All of these studies have shown that behavior similar to that of subjects 1.2 and 1.3 following the price change was a result of the price change and not random (Kagel, Battalio, Green, Basmann, and Klemm, 1975; Kagel, Battalio, and Green, 1995). In light of the results from these studies, and in consideration of the time and resources that would have been required to return the subjects to baseline, subjects 1.2 and 1.3 were not returned to baseline. It is reasonable to conclude that the present results are due to the difference in price between the baseline and experimental condition and are not random.

Subject 1.1. Subject 1.1 's response to the price change in the early session of each day was similar to that of subjects 1.2 and 1.3. However, in the later (ethanol) session the increase in the price of ethanol severely disrupted the subject's behavior causing intermittently high and low levels of responding for ethanol as well as erratic responding for the alternative commodity. Following the price change, the subject often failed to exhaust its allotted budget within the $45 \mathrm{~min}$. session time limit. In the non-ethanol control session, subject 1.1's price elasticity of demand for grape when choosing between that and cherry was $-0.94(t=-10.18)$. In the ethanol session, the price elasticity of demand for strawberry with $15 \%$ ethanol when choosing between that and orange was $-1.27(t=-6.99)$. Figures $4 a$ and $4 b$ show daily moving average intake levels for each session.

Due to its erratic behavior during the experimental segment of the ethanol session, this subject was returned to baseline parameters consistent with the ABA design. In the early non-ethanol control session subject 1.1 returned to its original baseline behavior. However, in the ethanol session consumption of ethanol increased but did not return to its original baseline level. Also, responding continued to be highly erratic. Figure 1 shows average daily intake under each condition: home cage, operant with the price of ethanol equal to 1 , and operant with the price of ethanol equal to 2 .

Control subject 1.4 and 1.C1. Subject 1.4 's results were similar to those of subjects 1.2 and 1.3 , helping to confirm that the difference in behavior between the ethanol and non-ethanol session was caused 
by the presence of ethanol rather than the differing times of these sessions. Subject 1.4's price elasticity of demand for grape when choosing between that and cherry was $-0.99(t=-6.53)$ and the price elasticity of demand for strawberry with $15 \%$ ethanol when choosing between that and orange was $-0.30(t=-4.07)$. Figures $7 \mathrm{a}$ and $7 \mathrm{~b}$ show the daily moving average intake levels for each session.

Subject 1.Cl's demand elasticities between two daily non-ethanol sessions were virtually identical, further supporting the case for ethanol being the cause of the behavioral differences between sessions in subjects 1.1, 1.2 and 1.3. In the early session, subject $1 . \mathrm{Cl}$ 's price elasticity of demand for strawberry when choosing between that and orange was $-1.05(t=-7.20)$ and, in the late session, the price elasticity of demand for cherry when choosing between that and grape was $-1.03(t=-5.38)$. Figures $8 \mathrm{a}$ and $8 \mathrm{~b}$ show the daily moving average intake levels for each session.

\section{Discussion}

In a within-subjects design rats were exposed to a variant of the Samson ethanol fading technique and then tested in two similar daily operant sessions, which differed primarily by the presence of ethanol as an alternative reinforcer in one of the sessions. Using operant testing procedures based on an economic model of consumer choice, changes in ethanol consumption due to the imposition of a budget and changes in relative price were measured. Results from the experiment provide information on ethanol consumption and economic choice behavior toward ethanol in rats with a history of ethanol exposure.

Ethanol was used as a commodity because of its addictive properties. The focus of this experiment was consumer choice behavior when one commodity in the choice set was addictive. Addictive commodities such as ethanol can be viewed as commodities whose current consumption depends on previous exposure; in other words, a commodity that reinforces its own consumption over time is addictive (Becker and Murphy, 1988). The use of the Samson fading procedure could be viewed as addicting rats to ethanol in that only through such past exposure were they willing to consume appreciable amounts of ethanol, although pharmacological addiction was not confirmed empirically in the present experiment.

Following exposure to ethanol via the Samson technique, subjects chose between concurrently available ethanol and non-ethanol sucrose commodities. Under this design it was unclear that ethanol was driving the consumption of the ethanol sucrose commodity, even though an alternative sucrose commodity 
was concurrently available. Subject 1.C2, the ethanol naive subject, confirmed that ethanol was driving the intake of the ethanol commodity; subject 1.C2 did not drink the ethanol sucrose commodity when an alternative non-ethanol sucrose commodity was concurrently available. This difference in behavior suggested that subjects that consumed ethanol were addicted in the sense that previous exposure, via the Samson sucrose fading technique, was necessary for current intake.

Comparison between the home cage, free choice intake levels and intake during the baseline operant condition also supports the hypothesis that subjects were addicted to ethanol following the Samson procecture, again in terms of the definition of addiction applied in economic theory (Becker and Murphy, 1988). In the home cage environment subjects $1.1,1.2$ and 1.3 consumed both the ethanol and non-ethanol commodities, and somewhat more of the non-ethanol commodity on average. When the total daily intake was limited by a $4 \mathrm{ml}$ budget constraint per daily session, and a response contingency, however, the subjects virtually gave up consumption of the non-ethanol commodity but maintained ethanol consumption near the home cage level. This suggests that the subjects were regulating ethanol intake in the home cage and that ethanol is highly reinforcing until some intake level, presumably near the home cage free choice level, is met. This argument explains why the subjects gave up almost all of the non-ethanol commodity when total intake was limited even though, in terms of total intake, they preferred the non-ethanol commodity in the home cage.

The next segment of the experiment utilized an economic model of consumer choice to compare the effect of a relative price increase on ethanol consumption versus a similar non-ethanol commodity. Comparison between the ethanol and non-ethanol control sessions revealed the effects of ethanol on economic choice behavior within each subject. Demand elasticities were estimated for each session using ordinary least squares regression techniques on equation (1). Results showed significant price change effects in each session and differences in the demand elasticities across sessions. Subjects 1.1, 1.2 and 1.3 all responded to the price change in the non-ethanol session by switching consumption toward the cheaper commodity. The demand elasticities reported here are similar to results reported in previous studies of the consumer choice model in rats (Kagel, Battalio, and Green, 1995) and indicate that prior ethanol exposure did not interfere with the subjects' ability to make decisions according to the maximizing principles of 
economic theory. Furthermore, when subject 1.1 was returned to baseline following the experimental condition, consumption returned to its original baseline levels. This suggests that the price change was responsible for all changes in behavior during the experimental condition and that the subject's preference structure was stable across conditions.

Subject 1.1, 1.2 and 1.3's response to the price change during the ethanol session indicate that ethanol is highly reinforcing in rats that previously had consumed significant amounts of ethanol. When the cost of attaining ethanol doubled in terms of lost non-ethanol sucrose opportunity, subjects 1.2 and 1.3 both initially decreased ethanol consumption in exchange for a relatively larger amount of the non-ethanol sucrose commodity per lever press. However, over subsequent testing days this behavior reversed itself and the subjects returned to exhausting almost all of their budget on the ethanol commodity. As a result, the subjects continued to maintain a level of ethanol intake near that of their home cage, free choice level. These findings are not consistent with the rational addiction hypothesis (Becker, Grossman, and Murphy, 1991) that long run elasticities be relatively larger than short run elasticities for addictive versus nonaddictive commodities.

Subject 1.1's behavior following the price change in the ethanol session was very erratic compared to subjects 1.2 and 1.3. This might be attributed to how the price change was initiated between the subjects. For subjects 1.2 and 1.3 the price change was initiated by increasing the volume per lever press on the non-etbanol solution and adjusting the budget downward while for subject 1.1 the volume of ethanol per lever press was reduced and the budget was adjusted upward. Although the magnitude of the price change was the same for all subjects, this operational difference required subject 1.1 to press the lever twice as many times as subject 1.2 and 1.3 in order to maintain baseline consumption levels. Regardless of this difference, subject 1.1's response to the price change during the non-ethanol session was similar to subjects 1.2 and 1.3. This difference may have had an influence on behavior during the ethanol session, however. Gnawing at the ethanol drinking trough was observed in subject 1.1 during the sessions immediately following the decrease in ethanol volume per lever press, perhaps indicating emotional or adjunctive behavior. When the parameters were returned to baseline, behavior remained erratic and did not return to original levels. Considering the erratic behavior and decrease in ethanol consumption during 
the experimental condition, the failure to return to baseline is consistent with the hypothesis that current ethanol consumption depends on prior intake levels. It also suggests that disruptions severe enough to decrease current intake also affect future intake.

The results from the operant control subjects helped confirm that ethanol was driving the behavioral differences between the ethanol and non-ethanol sessions observed in the experimental subjects. Subject 1.C2 was tested twice daily in two non-ethanol sessions which differed by Kool-Aid flavor and time of day. Results between the two sessions were nearly identical. Subject 1.4 was tested holding the time of day and prior daily testing constant. Results showed this control subject to be much less responsive toward the increase in the price of ethanol than toward the increase in the price of the nonethanol commodity. These results provide suggestive but not conclusive evidence that the factors associated with time of day and of prior daily testing did not contaminate the effects of alcohol observed in the behavior of subjects 1.1, 1.2 and 1.3. The control results reported here are across subjects and should be interpreted accordingly. An alternative, within subject, control procedure could have involved alternating the time the ethanol and non-ethanol sessions were run across days or weeks. However, running the subjects in this way would have required changing the time of day within the ethanol and non-ethanol sessions, introducing more severe control problems.

\section{Experiment \#1B}

\section{Overview}

During the first experiment, in general, the subjects' responses to the ethanol price increase were quite small. This result naturally raised the question of whether or not ethanol-experienced rats would respond more to a much larger price increase. To test this, when experiment \#1 A ended subjects 1.1, 1.2, and 1.3 were returned to their home cage, where, over a number of days, they received daily $30 \mathrm{~min}$. access to concurrently available plain sucrose and ethanol/sucrose solutions. The subjects were then tested for responses to a $400 \%$ increase in the price of ethanol using operant testing methods similar to those described in the $100 \%$ price change experiment. During ten days of baseline operant testing the total budget was set at $6 \mathrm{ml}$ 's and the price ratio was set at one. Over the following twenty days, the subjects faced a $400 \%$ increase in the relative price of ethanol. The price was changed by halving the 
ethanol/sucrose dispensed per lever press to $0.025 \mathrm{ml}$ and doubling the plain sucrose to $0.10 \mathrm{ml}$ per press. The budget was adjusted to hold real income constant. During the final ten days of operant testing, the price and budget were returned to baseline.

In addition to the larger price change, there were other differences in experiment \#1B. The subjects were only tested once daily in the operant chamber, choosing between an ethanol/sucrose and a plain sucrose commodity. The baseline budget was larger at $6 \mathrm{ml}$ compared to $4 \mathrm{ml}$. No control subjects were used since no comparison between the effect of the $400 \%$ price increase on ethanol versus nonethanol consumption was made. Following the price change condition all of the subjects were returned to baseline. Finally, the subjects were tested over a shorter number of test days.

\section{Results}

In general, subject 1.1,1.2, and 1.3's preferences for the plain sucrose and ethanol/sucrose commodities were similar to those exhibited during the $100 \%$ price change experiment. Responses to the $400 \%$ ethanol price increase were more pronounced, however.

Home cage intake. Subjects 1.1, 1.2, and 1.3 consumed both ethanol and non-ethanol sucrose commodities when they were concurrently available in the home cage. Average intake of each commodity was similar for all three subjects. Each drank more of the plain sucrose commodity than of the ethanol sucrose commodity, indicating that there was no preference for the ethanol sucrose commodity when both were freely available. Average intake over the ten day period can be seen in the "Home Cage" bars in Figures 9-11.

Home cage intake versus baseline operant intake. During the baseline operant period subjects 1.1, 1.2 and 1.3 exhausted most of their budgeted $6 \mathrm{ml}$ of liquid on the ethanol commodity. Average daily ethanol intake was just over $4 \mathrm{ml}$ for each subject during the baseline operant sessions, representing a small decline relative to home cage intake. On the other hand, consumption of the non-ethanol commodity fell dramatically, as would be required to maintain near home cage ethanol levels given the limited budget of the baseline operant sessions. Intake of the non-ethanol commodity for subjects 1.1, 1.2 and 1.3 fell by $6.76 \mathrm{ml}, 5.84 \mathrm{ml}$ and $9.71 \mathrm{ml}$ respectively. The bar graphs labeled "Home Cage" and 
"Operant Price Etoh=1" in Figures 9-11 illustrate the magnitude of the changes in consumption between the two conditions.

Operant intake - the effect of a $400 \%$ price increase on the consumption an ethanol commodity. Subjects 1.1, 1.2, and 1.3 all responded to the increase in the price of ethanol by reducing consumption of the ethanol commodity. Subject 1.1's price elasticity of demand for ethanol was $-1.25(t=-6.26)$. Subject 1.2 's price elasticity of demand for ethanol was $-0.59(\mathrm{t}=-12.35)$. Subject 1.3 's price elasticity of demand for ethanol was $-0.83(t=-6.26)$. The bag graphs labeled "Operant Price Etoh=1" and "Operant Price Etoh=4" in Figures 9-11 illustrate the magnitude of the changes in consumption in response to the price change.

Return to operant baseline. Subjects 1.1,1.2, and 1.3 were returned to operant baseline following the $400 \%$ price change condition. Consumption behavior for each subject returned to near its original operant baseline level. The bar graphs labeled "Operant Price Etoh=1", "Operant Price Etoh=4" and "Operant Price Etoh=1" in Figures 9-11 illustrate the return to baseline response.

\section{Discussion}

Experiment \#1B represents an extension of experiment \#1A. The decision to conduct the experiment was made following the observation of small consumption effects in response to a $100 \%$ increase ethanol's price. The purpose of \#1B was to attempt to ascertain whether a larger increase in the price mechanism would result in a similar, small, response. Experiment \#1B was conducted using the same subjects and similar procedures as experiment \#1A.

To begin experiment \#1B the subjects were returned to their home cage and given daily $30 \mathrm{~min}$. access to concurrently available plain sucrose water and ethanol sucrose water solutions. Doing this essentially replicated the initial home cage condition of experiment \#1A, with the exception that no KoolAid flavors were involved Comparing the "Home Cage" bars in Figures 1, 2, 3 from experiment \#1A to the "Home Cage" bars in Figures 9, 10, 11 from \#1B shows very similar relative intakes. Again, each subject drank more plain sucrose solution relative to ethanol solution, confirming that plain sucrose was preferred to ethanol sucrose when both were freely available. 
The subjects were then tested in an operant chamber similarly to experiment \#1 A. A budget and equal prices were first imposed. Behavior was nearly identical to the similar circumstance in \#1A. In response to the limited income, all subjects dramatically reduced plain sucrose consumption and maintained near home cage ethanol intake, again confirming the behavior in \#1A. This behavior suggests that the subjects seek to maintain some minimum ethanol intake level.

The subjects behavior in response to a $400 \%$ increase in ethanol's price was significantly different from their response to the $100 \%$ increase in experiment \#1A. All of the subjects responded by dramatically reducing ethanol consumption. This result suggest that significant increases in ethanol's price, measured by the forgone opportunity to consume an alternative plain sucrose commodity, influences ethanol consumption. Also, for experiments \#1A and \#1B the magnitude by which each subject responded to the change in price was of similar order - subject 1.2 's elasticity was relatively smallest, 1.3 's $2 \mathrm{nd}$, and 1.1's largest.

Caution must be taken when making comparisons between \#1A and \#1B, however. During \#1B there was no earlier non-ethanol operant session, fearing that an earlier $400 \%$ price change session might cause satiation prior to the later ethanol session. As such, it is possible that ethanol's relative value differed between \#1A and \#1B. However, relative ethanol consumption during the similar baseline conditions of experiments \#1A and \#1B was nearly identical, suggesting the magnitude of the price change was primarily responsible for behavior differences in \#1A and \#1B.

Finally, \#1B returned the subjects to the baseline conditions. As can be seen in figures 9 and 10 , subject 1.1 and 1.2's ethanol intake did not completely return to its higher baseline level. Although clearly inconclusive, such behavior is consistent with the notion that an addictive commodity, such as ethanol, is a time complement. More importantly, the general return to baseline by each subject strongly suggests that the reduced ethanol intake during the experimental condition was a direct result of ethanol's increased price.

\section{Experiment \#2}

Introduction 
Experiment \#2 measured rats responses to increases in the future price of ethanol. The experiment served two objectives. First, to test whether rats would respond to signaled future price increases in a way suggested by the theory of rational addiction (Becker and Murphy, 1988). That is, would current ethanol consumption decline in response to an anticipated increase in price. Rats were tested similarly to experiment \#1, but faced two independent concurrent budgets within each daily session - a first budget with one set of prices and, following the first budget's exhaustion, a second budget with new prices. Signaled and unsignaled price changes were imposed during the second budget, providing a circumstance to measure the signal's effect on current consumption. By looking at responses to a future price change, the design directly tests the rational addiction hypothesis. Second, the experiment provides an alternative approach for measuring the effects of price changes on consumption. In this experiment, as with experiment \#1, the subjects were tested for responses to price changes using ethanol and non-ethanol commodities.

\section{Methods}

\section{Subjects}

Similar to experiment \#1, four adult male, 60-80 day old Sprague-Dawley rats from our laboratory's breeding facility (rats 2.1, 2.2, 2.3, and 2.4) were singly housed in standard hanging cages in a temperature and light controlled colony room. Subjects had ad lib. access to water and standard laboratory rat chow while in their home cage.

\section{Experimental design}

Overview. Following standard operant shaping, the subjects lever pressed for concurrently available alternative commodities, including ethanol, and then, over subsequent test days, budgets and relative prices were imposed. The subjects were tested twice daily under these conditions, choosing between two alternative sucrose flavors in an early, control session and between plain sucrose and an ethanol/sucrose solution in a late, experimental session (subject 2.4 was tested only once daily during the experimental session).

Unlike experiment \#1, which studied responses to a single permanent price change midway through the experiment, this experiment studied responses to price changes which took place within the 
daily sessions. Behavior under three experimental conditions was studied -- daily sessions without a price change (condition 1), daily sessions with an unsignaled price change (condition 2), and daily sessions with a price change that was signaled prior to its $\propto$ ccurrence (condition 3 ). The three conditions were alternated at random over consecutive test days, allowing each to occur numerous times. The subjects were exposed to the various conditions for two reasons: First, to determine if signaled changes in the future price of ethanol affected behavior in a way implied by intertemporal complementarity; second, to study responses to price changes which occurred within a session for ethanol and non-ethanol commodities.

Home cage ethanol exposure. Subjects were trained to consume ethanol via a variant of the Samson sucrose-ethanol fading technique (Samson, 1986). The technique was similar to that described in experiment \#1.

Operant shaping Subjects were trained to lever press for concurrently available commodities using techniques similar to the those described in experiment \#1.

Operant design Subjects choose between a 10\% sucrose/grape Kool-Aid solution on lever 1 and a $10 \%$ sucrose/cherry Kool-Aid solution on lever 2 during the early (12:30 - 1:30 p.m.) daily control sessions and between a $10 \%$ plain sucrose solution on lever 1 and $15 \%$ ethanol/10\% sucrose solution on lever 2 during the late (2:30 - 3:30 p.m.) experimental sessions, with all solutions being dispensed in 0.05 $\mathrm{ml} /$ reinforcement increments. Each daily testing session was divided into two sequential independent periods, defined as the first and second budgets respectively. At the start of a session, the subject faced a price ratio associated with the first budget. Immediately following the exhaustion of the first budget, the computer reset and initiated the second budget, along with its associated price ratio. When the second budget was exhausted the white lights above the levers went off and the session ended. Dividing the daily sessions into two independent budgets allowed within-session price changes and response to a signaled future price change to be studied. A 7.5 watt green light and $80 \mathrm{db}$ Sonalert, mounted inside the operant chamber, were used as a cue curing the first budget to signal an impending price change at the onset of the second budget. 
Initially the subjects were tested for five days, receiving 40 lever presses and facing a price ratio of 1 ( FR-1 on both levers) during each of the two budgets. Based on median intake, the five days of data were used to determine Slutsky income held constant budgets for the two conditions that involved a price change ( from FR-1 to FR-2 on lever 2) during the second budget of the session. Next, the three possible budget and price conditions were randomly applied over 30 consecutive days. Condition 1 was the baseline condition. Under this condition the number of lever presses and price ratios were identical during the first and second budgets of each session. Condition 2 involved an unanticipated price change during the second budget. During the first budget of condition 2 all of the parameters were identical to condition 1. However, during the second budget the number of lever presses required to obtain a reinforcement on lever 2 doubled to FR-2 and the lever presses were adjusted, based on baseline information, to hold income constant. This difference effectively doubled the price of cherry and ethanol during the second budget of condition 2. Condition 3 was similar to condition 2 except that a cue, in the form of a green light and $80 \mathrm{db}$ Sonalert, was on throughout the first budget. The cue served to signal the impending price change at the onset of the second budget and was extinguished when that budget began.

To test whether the subjects responded to the cue in a way implied by rational addiction (Becker and Murphy, 1988), their behavior during the first budget of each of the three experimental conditions was compared. In the absence of a cue during the first budget of conditions 1 and 2, the subjects could not determine if the price would change at the onset of the second budget. As a result, first budget behavior between these conditions should have been similar for both the control and experimental sessions. During condition 3 the cued first budget was always followed by a price change at the onset of the second budget. If the subjects were able to associate this cue with the impending price change then, according to rational addiction, their behavior should have been affected during the ethanol session only. In other words, behavior during the first budget of the control sessions should have been similar across all three conditions and condition 3 should have differed from conditions 1 and 2 during the first budget of the ethanol sessions. Specifically, since the hypothesis predicts complementarity and the price of ethanol increased, consumption should have been lower, relative to conditions 1 and 2 , during the first budget of condition 3. Comparing the conditions in the ethanol session directly tests the hypothesis that ethanol is 
an intertemporal complement, while comparing conditions in the non-ethanol session controls for influences of the cue irrespective of it's meaning. The final 27 days of testing were used in the analysis -providing 9 days of data for each condition.

\section{Results}

\section{Commodity preference}

Introduction. During the control and experimental sessions subjects choose between cherry sucrose or grape sucrose commodities and ethanol/sucrose or plain sucrose commodities respectively under varying conditions and prices. The subjects preference for one commodity (.05 ml/reinforcement) vs. an alternative commodity (.05 ml/reinforcement) was measured by looking at the how the subjects allocated their 40 lever press $(2 \mathrm{ml}$ ) budget (subject 2.4's budget was 50 presses or $2.5 \mathrm{ml}$ ) between the two commodities when the price ratio was 1 (FR-1 for both commodities). Table 2 shows the testing parameters for each subject.

Comparisons During the experimental session subject 2.1 consumed the ethanol/sucrose commodity exclusively. During the control session subject 2.1 consumed both commodities but often failed to use all of its 40 lever press budget during the allotted $45 \mathrm{~min}$. time period. Such a result is interesting since sucrose was the vehicle used to make ethanol more palatable during initial exposure Subject 2.2 consumed, on average, $1.86 \mathrm{ml}$ of the ethanol/sucrose commodity and $0.14 \mathrm{ml}$ of the sucrose commodity during the experimental sessions, and $1.60 \mathrm{ml}$ of the cherry sucrose and $0.40 \mathrm{ml}$ of the grape sucrose during the control sessions. Subject 2.3 consumed equal quantities of the two commodities during both the experimental and control sessions. Subject 2.4 consumed, on average, $2.12 \mathrm{ml}$ of the ethanol/sucrose commodity and $0.38 \mathrm{ml}$ of the sucrose commodity during the experimental session, and was not tested during the control session. These intake comparisons suggest that ethanol is reinforcing for ethanol-experienced rats. As such, they support the results of experiment \#1. Table 2 reports the consumption data for each subject under each parameter.

\section{Within-session prices changes}

Consumption between similarly priced first and second budgets - condition 1 . In the experimental session subjects $2.1,2.2,2.3$, and 2.4 showed no statistical difference $(\mathrm{p}>0.05)$ when comparing 
consumption between the first and second budgets of condition 1 (the no price change condition).

Similarly, in the control session subjects 2.2 , and 2.3 showed no statistical difference $(P>0.05)$. Subject 2.1's consumption was significantly different between control session budgets, primarily, as mentioned above, because subject 2.1 often failed to exhaust it's second budget. Such behavior influenced all of subject 2.1's control session results, making their interpretation questionable.

Consumption between alternatively priced first and second budgets - conditions $2 \& 3$. Over the 27 days of operant testing, subjects $2.1,2.2$ and 2.3 were exposed to total of 36 within-session price changes, while subject 2.4 was exposed to 18 . Subjects $2.1,2.2$, and 2.4 responded to every price change by reducing consumption of the commodity which increased in price. Subjects 2.3 responded to 31 of the 36 price changes by reducing consumption of the commodity which increased in price. Subject 2.1 's responses to the price changes in the control sessions were hard to interpret because the subject often failed to exhaust its second budget - consuming less of both cherry and grape, irrespective of a price change. Subject 2.1's ethanol consumption decrease by a negligible amount, on average, in response to the price increases. Subject 2.2 's ethanol consumption decreased by only half as much as cherry consumption, on average, in response to the price increases. Subject 2.3's ethanol consumption decreased by slightly more than cherry consumption, on average, in response to the price increases. Interestingly, subject 2.3 showed the weakest preference for ethanol during the first budgets, prior to the price changes. These results are consistent with the results of experiment \#1 regarding ethanol preferences. In addition, they suggest that the response to a change in the price of ethanol is a function of the preference for ethanol. Table 2 reports the intake comparisons for each subject.

\section{Signaled future price changes}

Rational addiction (Becker and Murphy, 1988) implies that a forward looking addicted consumer will currently reduce consumption of the addictive commodity in response to an anticipated increase in its future price. To test this, average ethanol consumption during the first budget for each condition was compared. As a control, average cherry consumption was similarly compared. The first budget for each condition had similar parameters, with the exception being that condition 3 included a cue to signal an impending price increase. Under rational addiction, the cue, if properly interpreted, should illicit a 
relative decrease in ethanol consumption during that budget, while there should be no relative change in cherry consumption.

Comparisons of first budget consumption levels for both ethanol and cherry were made across conditions (e.g., condition 1 vs. 2,1 vs. 3 , and 2 vs. 3 ). In the control session there were no significant (P $>$.05) differences in cherry consumption across conditions for any of the subjects. This result suggests two things: First, that the subjects' day to day preferences were stable; second, that the cue in itself did not affect behavior. In the experimental sessions there was no significant differences $(P>0.05)$ in ethanol consumption across all three conditions for any of the subjects. As such, the findings are not consistent with the rational addiction hypothesis (Becker and Murphy, 1988) that addicted consumers currently respond to anticipated changes in the future price of an addictive commodity. Failure to respond to the cue is attributable to a number of possible causes. First, and most likely, the cue may not have been interpreted as a signal of future price change. Unfortunately, it is impossible to confirm such an understanding independent of rational addictive behavior. The subjects did show an awareness to the cue, noted by sniffing and rearing toward it, but this in no way suggests that it was understood. Second, the cue may have been understood but the subjects' addiction to the ethanol was weak - with rational addiction, the degree of addiction (intertemporal complementarity) drives the magnitude of the current response to anticipated price changes for addictive commadities. Third, rats may lack the sophistication necessary to consider future events in a utility maximizing framework.

\section{General Conclusions}

This study utilized economic models of consumer choice to study the demand for an addictive commodity. Our approach differs dramatically from current economic studies of addictive consumption. By adopting the experimental psychologist's controlled experiment methodology we were able compare the impact of a given price change on addictive and non-addictive consumption. Because traditional economists do not use controlled experiments this result has not before been attainable. Further, the results provide new information on the reinforcing effects of ethanol in rats.

The focus of this study was to compare demand elasticities between addictive and non-addictive commodities and to look at economic theorems of addictive behavior. We employed ethanol because it 
exhibits addictive properties. Using the Samson (1986) fading procedure rats were addicted to ethanol. Two theorems were considered. First, long run elasticities are relatively larger than short run elasticities for addictive versus non-addictive commodities (Becker, Grossman, Murphy, 1991). Second, past and future price affect behavior, as opposed to only current price which is typical for non-addictive commodities (Becker, and Murphy, 1988).

We confirmed Samson's (1986) finding that rats can be induced to consume ethanol. The procecture essentially "addicted" rats to ethanol, suggesting current ethanol intake is a function of past consumption. The rats consumed an appreciable amount of ethanol/sucrose commodity but did not prefer it to a similar sucrose commodity when both were freely available. However, imposing a budget to limit total daily intake resulted in dramatic reductions in sucrose consumption while hardly affecting ethanol/sucrose intake. The result suggests that ethanol is very reinforcing until a minimum intake level (presumably near the free choice level) is attained.

Second, we found that changes in current price affected behavior. This was true for both nonethanol as well as ethanol commodities. Where comparisons were made, responses to ethanol price changes were typically smaller than responses to non-ethanol price changes. A result which again suggests that ethanol is very reinforcing. In experiment \#1 A a 100\% increase in ethanol's price only reduce it's consumption by marginal amounts. Over time, responses to the price change tended to become smaller, suggesting that long run elasticities are not larger that short run elasticities. In experiment \#1B, a $400 \%$ increase in ethanol's price dramatically reduced ethanol consumption. These results suggest that human addicts may also be susceptible to dramatic changes in price. As such, public policy makers might consider using increased taxes as a mechanism to minimize addiction.

Third, we did not find evidence in support of the hypothesis that an addicted consumer will currently respond to an anticipated future change in price. In experiment \#2 a cue which signaled an impending increase in ethanol's price did not cause immediate rechuctions in ethanol consumption. This result cannot, however, reject the hypothesis, as it is likely that the rats did not understand the implication of the cue. Our future research will spend more time training rats to understand future price change 
signals. Regardless, experiment $\# 2$ is of value - its controlled design represented the first direct attempt to confirm the hypothesis and it corroborates results from experiment \#1. 


\section{References}

Becker, G. S. \& Murphy, K.M. A theory of rational addiction. Joumal of Political Economy 96: 675-700; 1988.

Becker, G.S., Grossman, M., \& Murphy, K. M. An emperical analysis of cigarette addiction. American Economic Review 84: 396-418; 1994.

Becker, G.S., Grossman, M., \& Murphy, K.M. Rational addiction and the effect of price on consumption. Amenrican Economic Review 84: 237-241; 1991.

Bickel, W. K., Hughes, J. R., DeGrandpre, R. J., Higgins, S. T. \& Rizzuto, P. Behavioral economics of drug self-administration: The effects of response requirement on the consumption of and interaction. between concurrently available coffee and cigarettes. Psychopharmacology 107: 211-216; 1992.

Chaloupka, F. Rational addictive behavior and cigarette smoking. Journal of Political Economy 99: 722$742 ; 1991$.

Grossman, M., Chaloupka, F., \& Brown. The demand for cocaine by young adults: A rational addiction approach. National Bureau of Economic Research Working Paper Series: Paper 5713; 1996.

Grossman, M., Chaloupka, F. \& Sirtalan, I. An empirical analysis of alcohol addiction: Results from the monitoring the future panels. National Bureau of Economic Research Working Paper Series: Paper 5200; 1995.

Kagel, J., Battalio, R. \& Green, L. Economic choice theory: An experimental analysis of animal behavior. NY: Cambridge University Press; 1995.

Kagel, J., Battalio, R., Rachlin, H.,Green, L, Basmann, R.L. \& Klemm, W. Experimental studies of consumer demand behavior using laboratory animals. Economic Inquiry 13: 22-38; 1975.

Meisch R. A. \& Thompson, T. Ethanol as a reinforcer: Effects of fixed ratio, size and food deprivation. Psychopharmacologia 28: 171-183; 1973.

Mobilia, P. An economic analysis of addictive behavior: the case of gambling. Ph.D. dissertation, City University of New York Graduate School, 1990.

Samson, H. H. Initiation of ethanol reinforcement using a sucrose substitution procedure in food- and water-sated rats. Alcoholism: Clinical and Experimental Research 10: 436-442; 1986. 

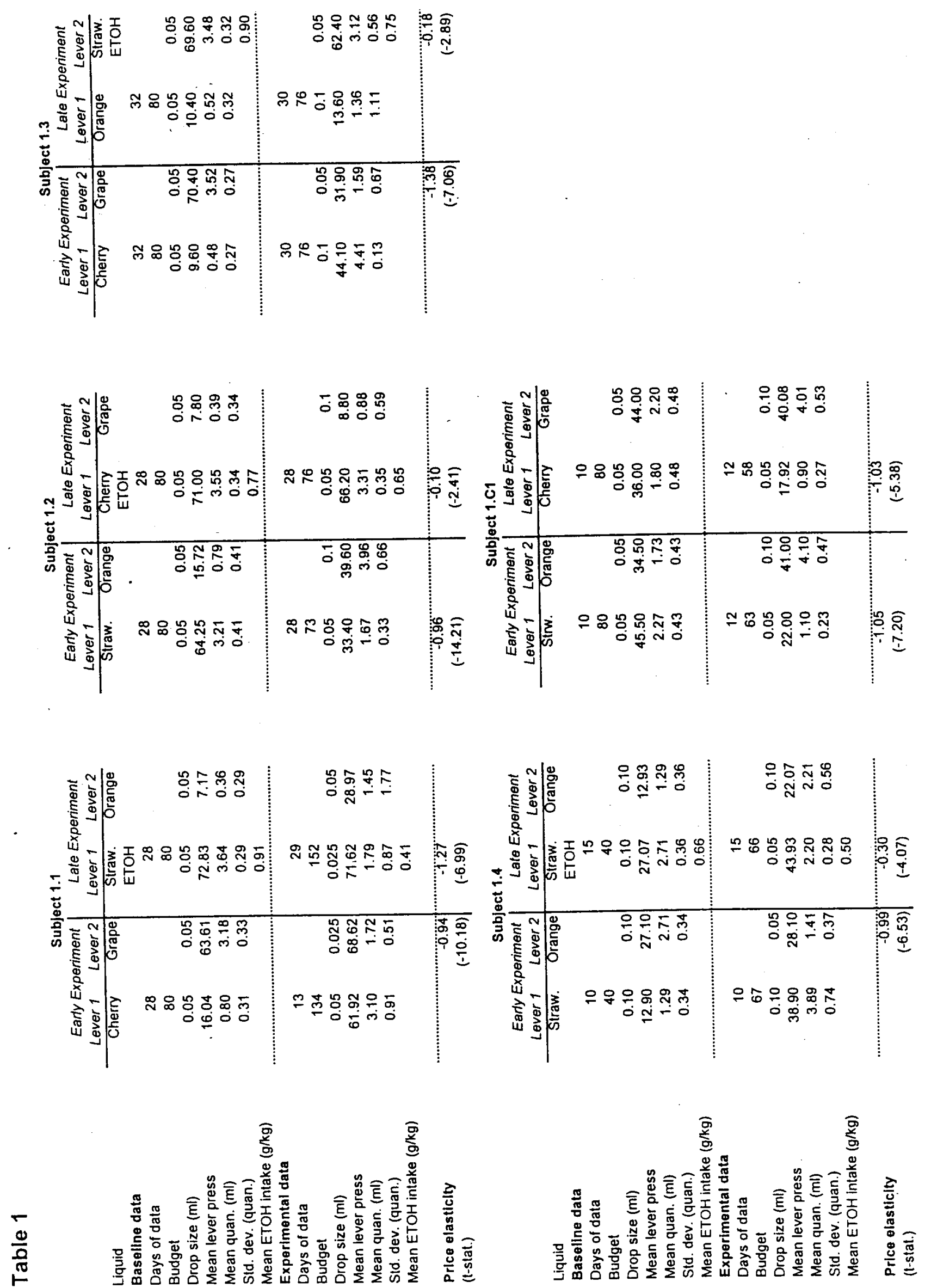


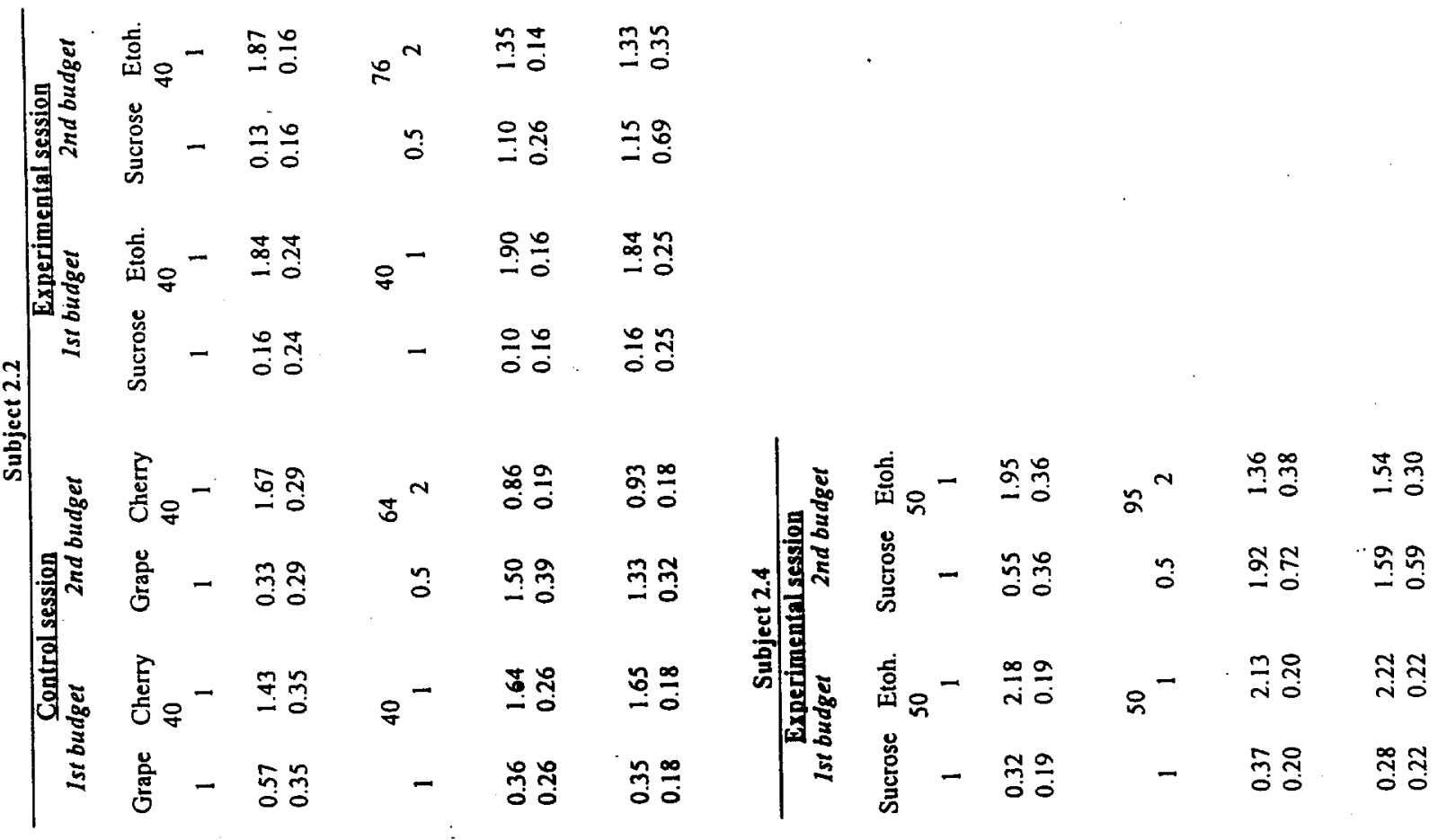
| 氧

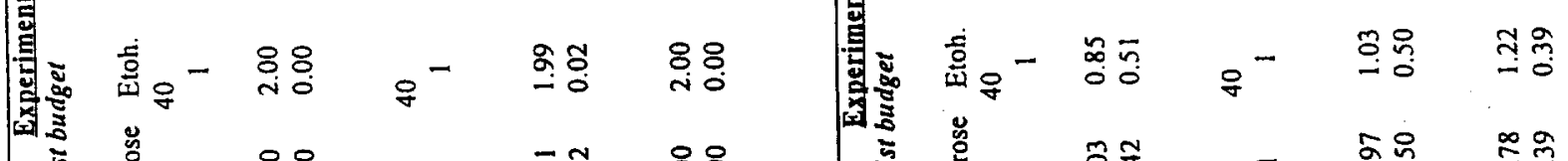
泀

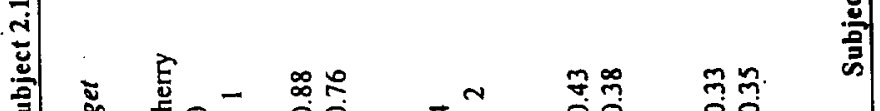

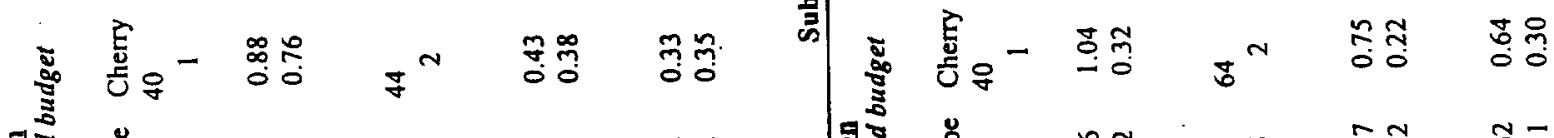

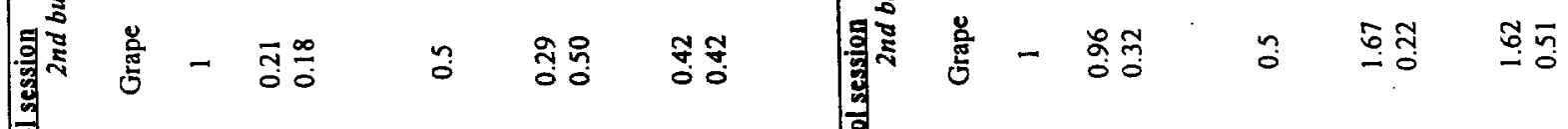

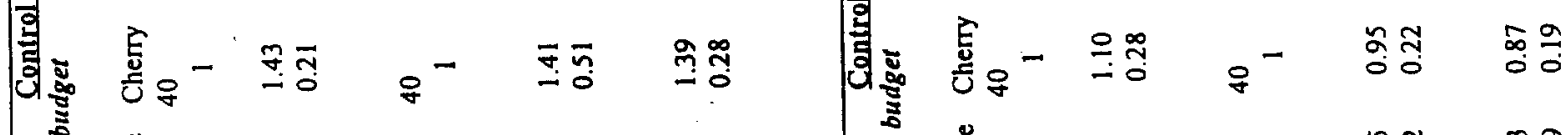

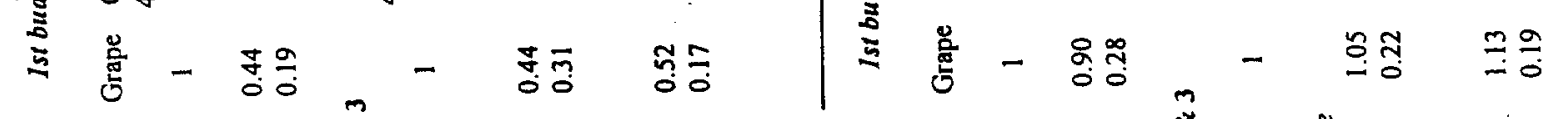

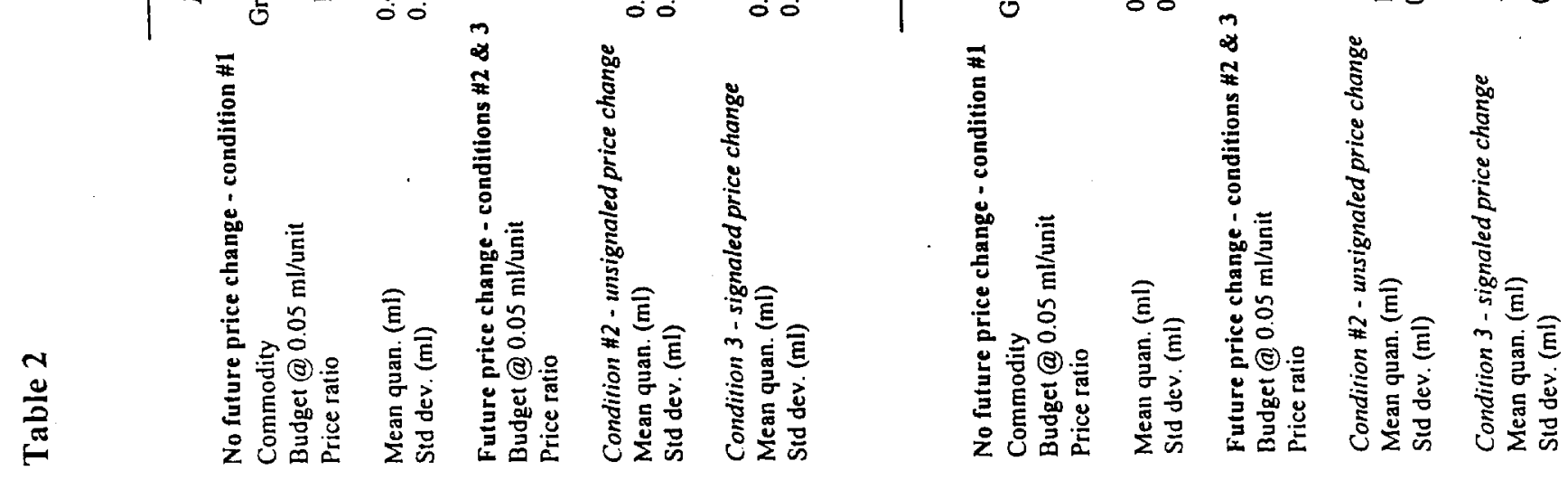


Figure 1: Home Cage vs. Operant Intake

Subject 1.1

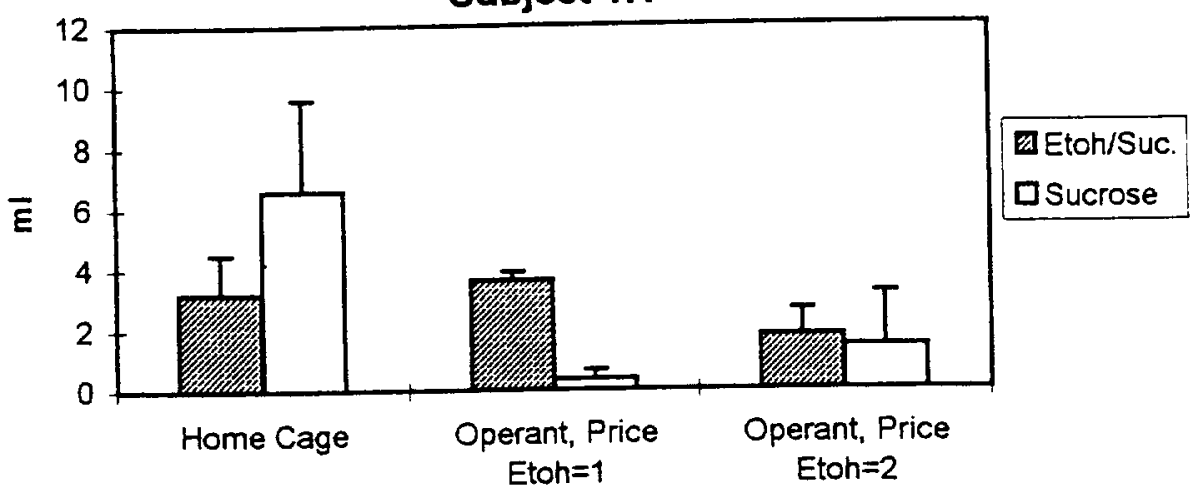

Figure 2: Home Cage vs. Operant Intake

Subject 1.2

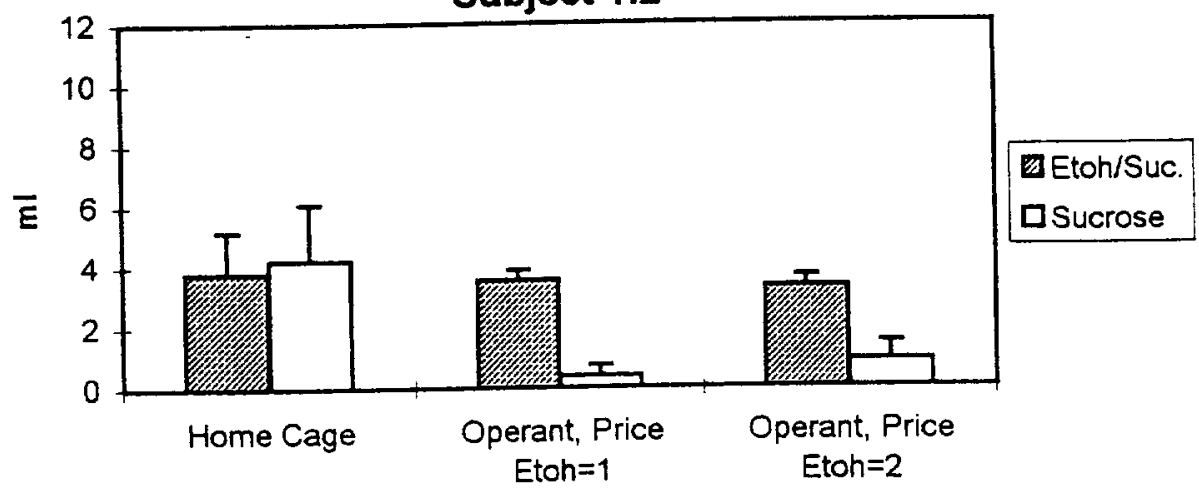

Figure 3: Home Cage vs. Operant Intake Subject 1.3

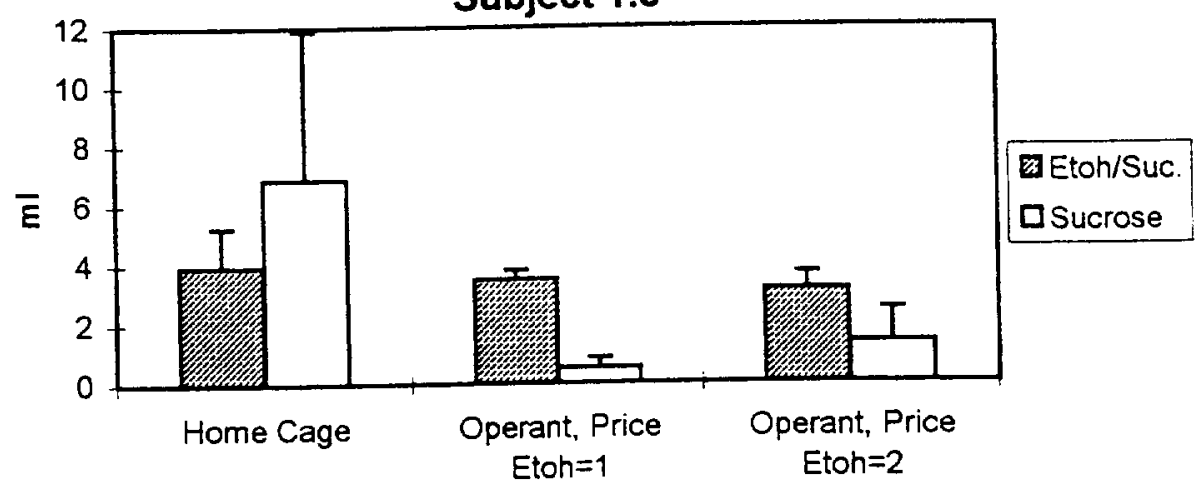


Figure 4a: subject 1.1 - non-ethanol control

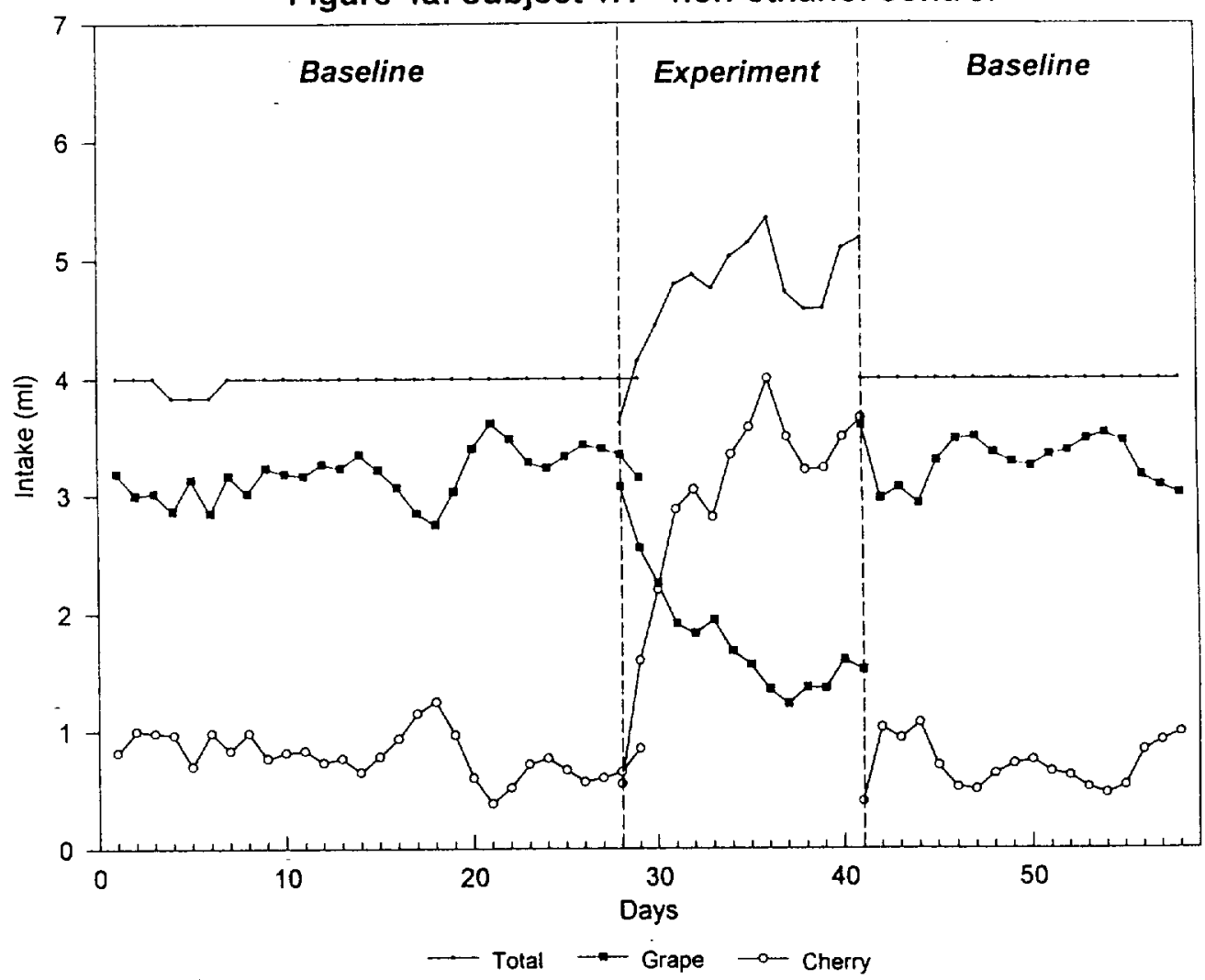

Figure 4b: subject 1.1 - ethanol session

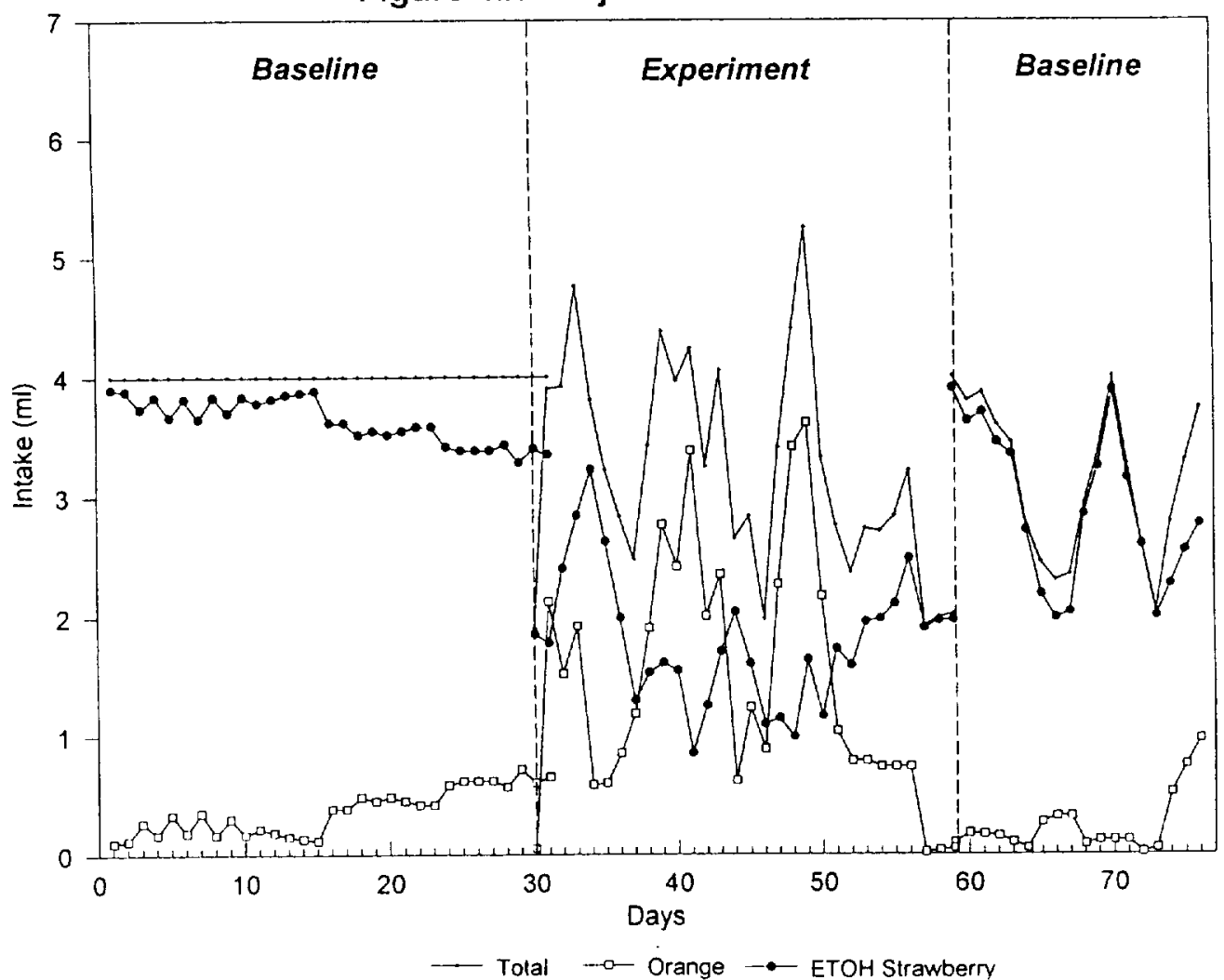


Figure 5a: subject 1.2 - non-ethanol control

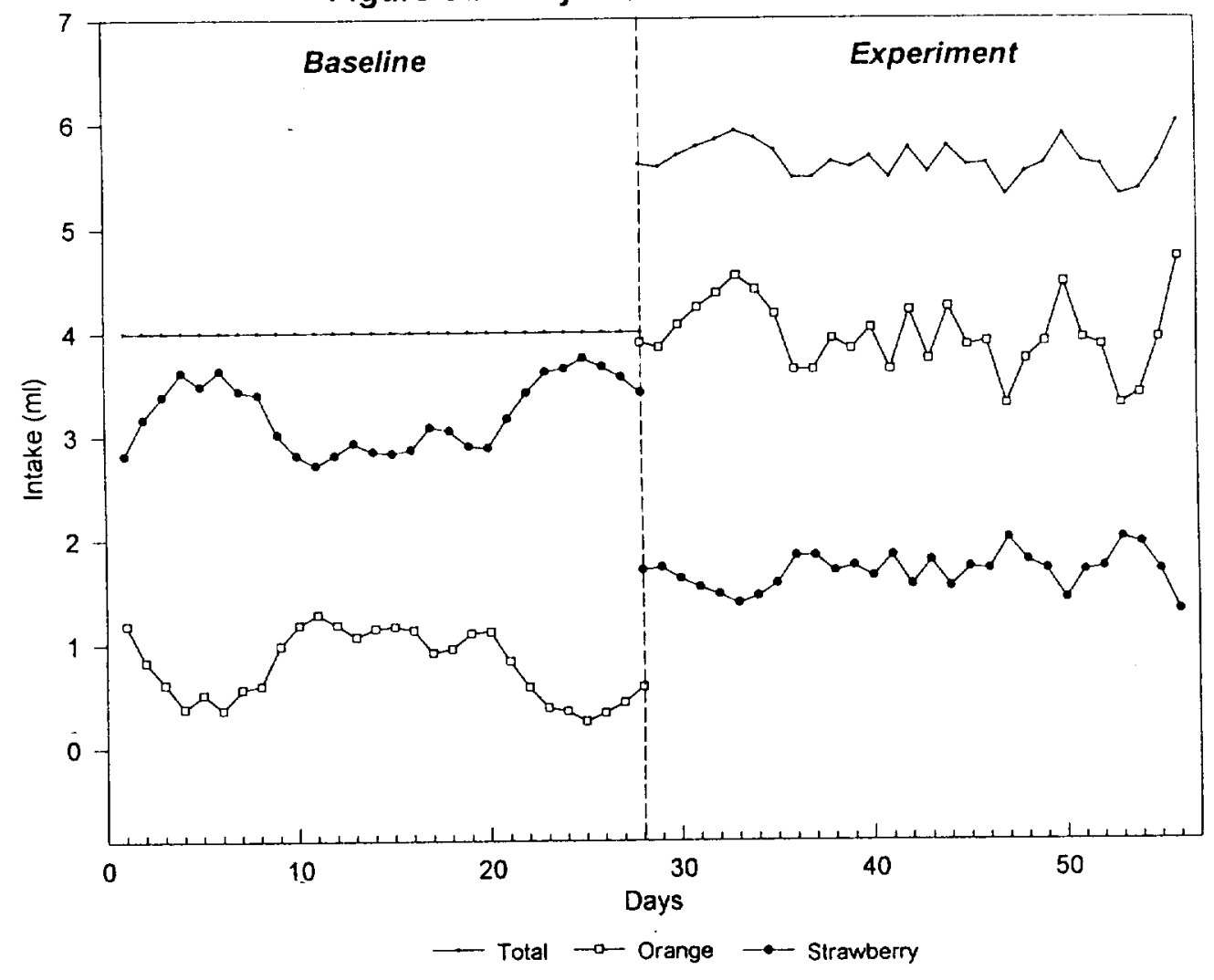

Figure 5b: subject 1.2 - ethanol session

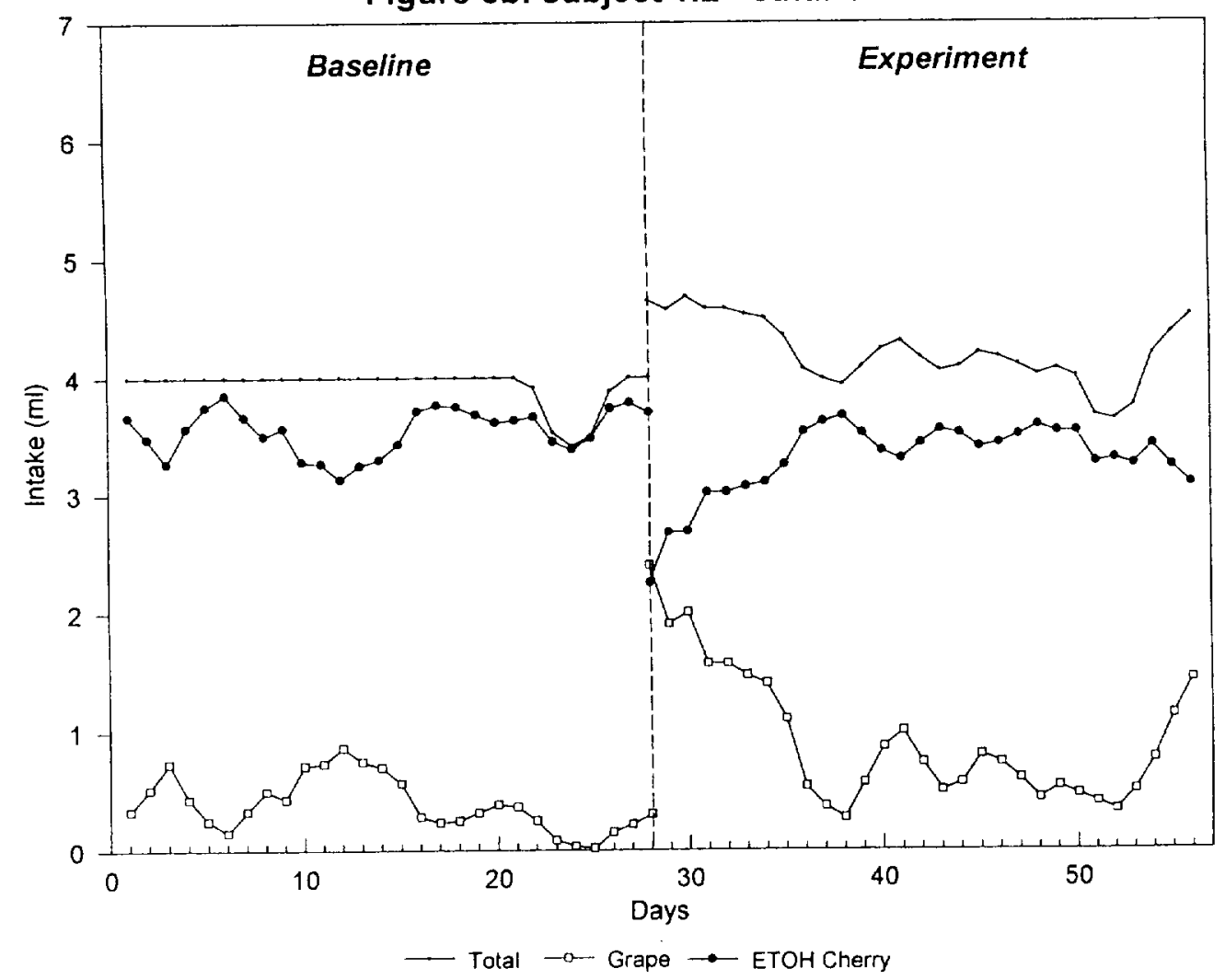


Figure 6a: subject 1.3 - non-ethanol control

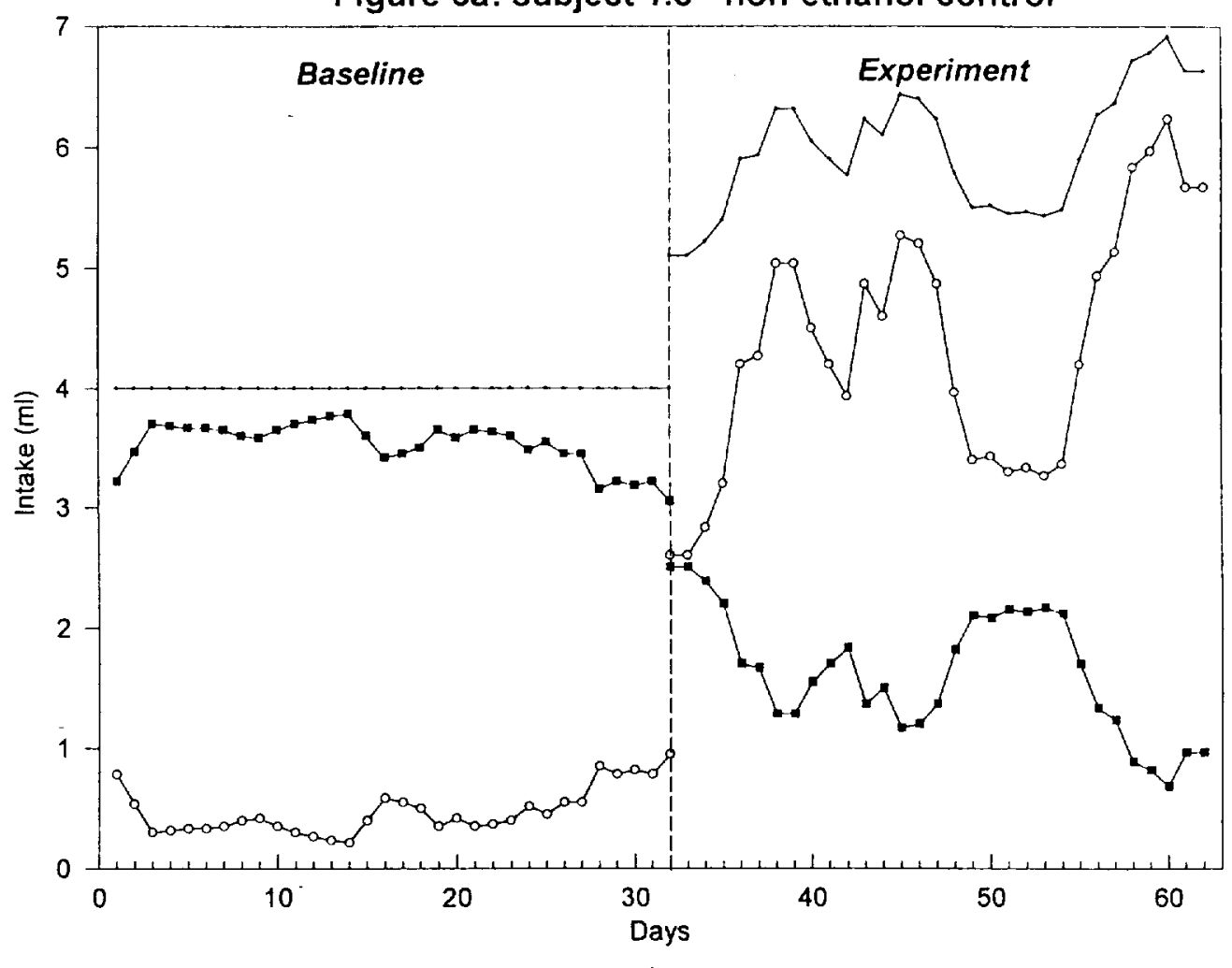

$\longrightarrow$ Total -- Grape $\rightarrow$ Cherry

Figure 6b: subject 1.3 - ethanol session

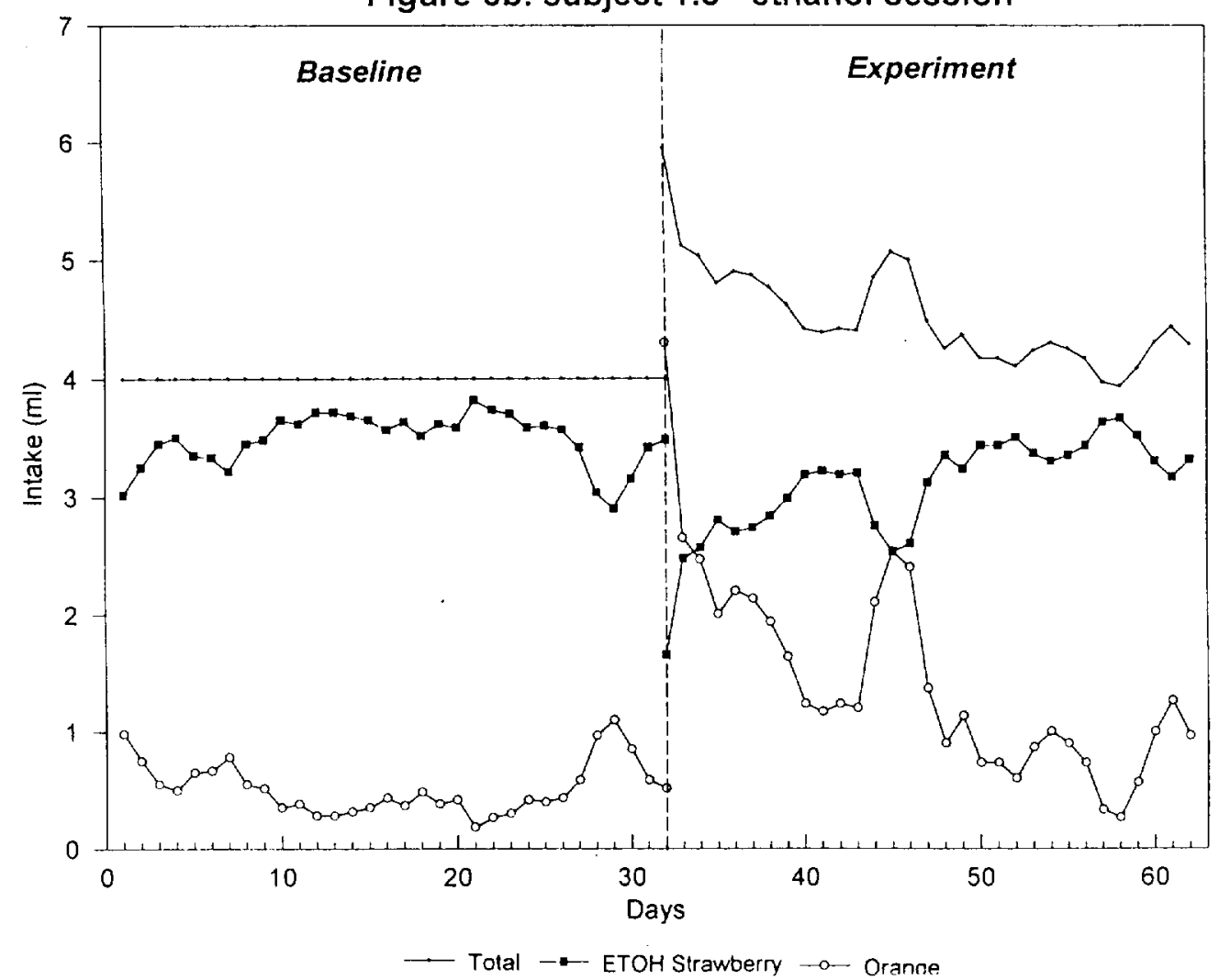


Figure 7a: subject 1.4 - non-ethanol control

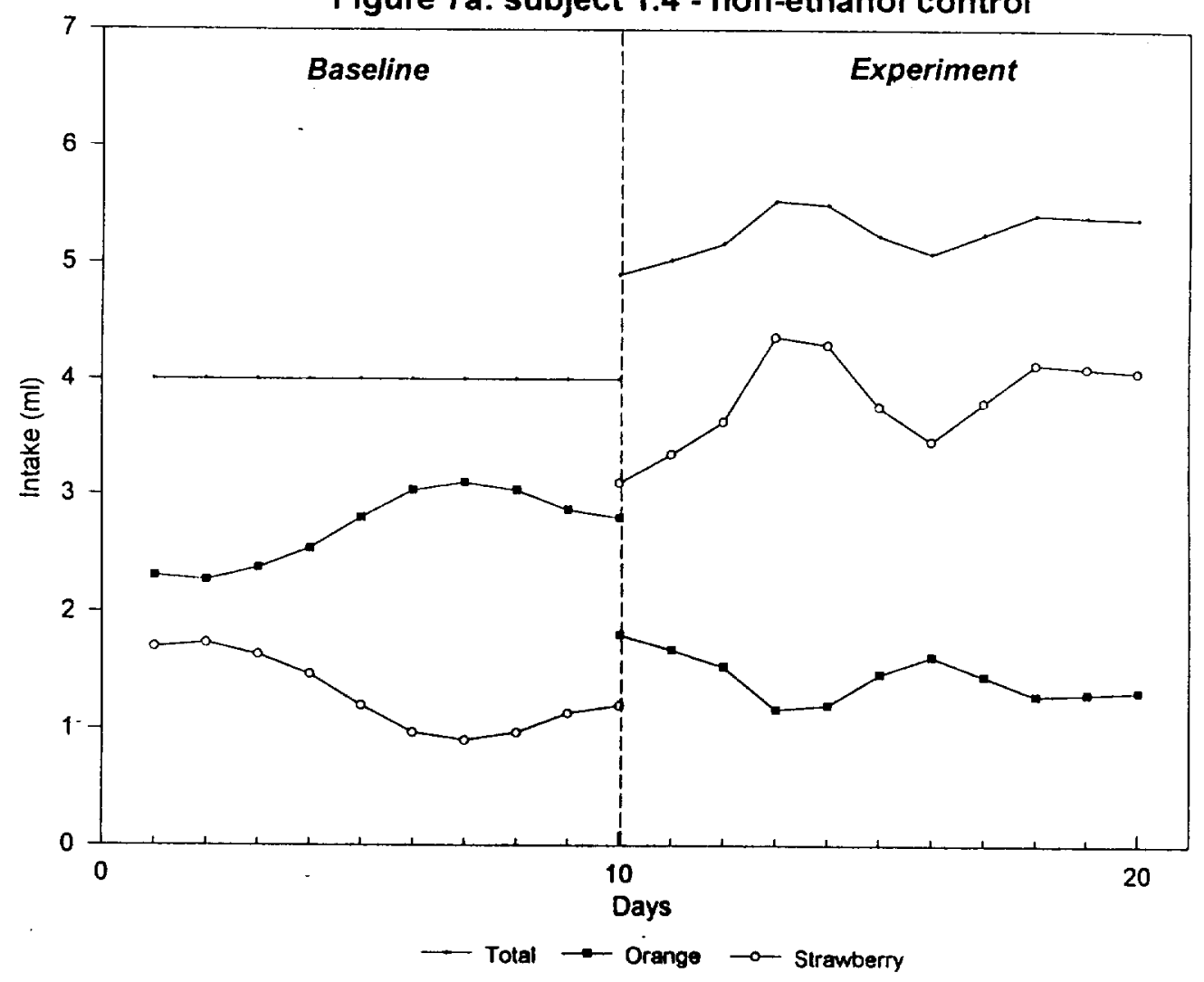

Figure 7b: subject 1.4 - ethanol session

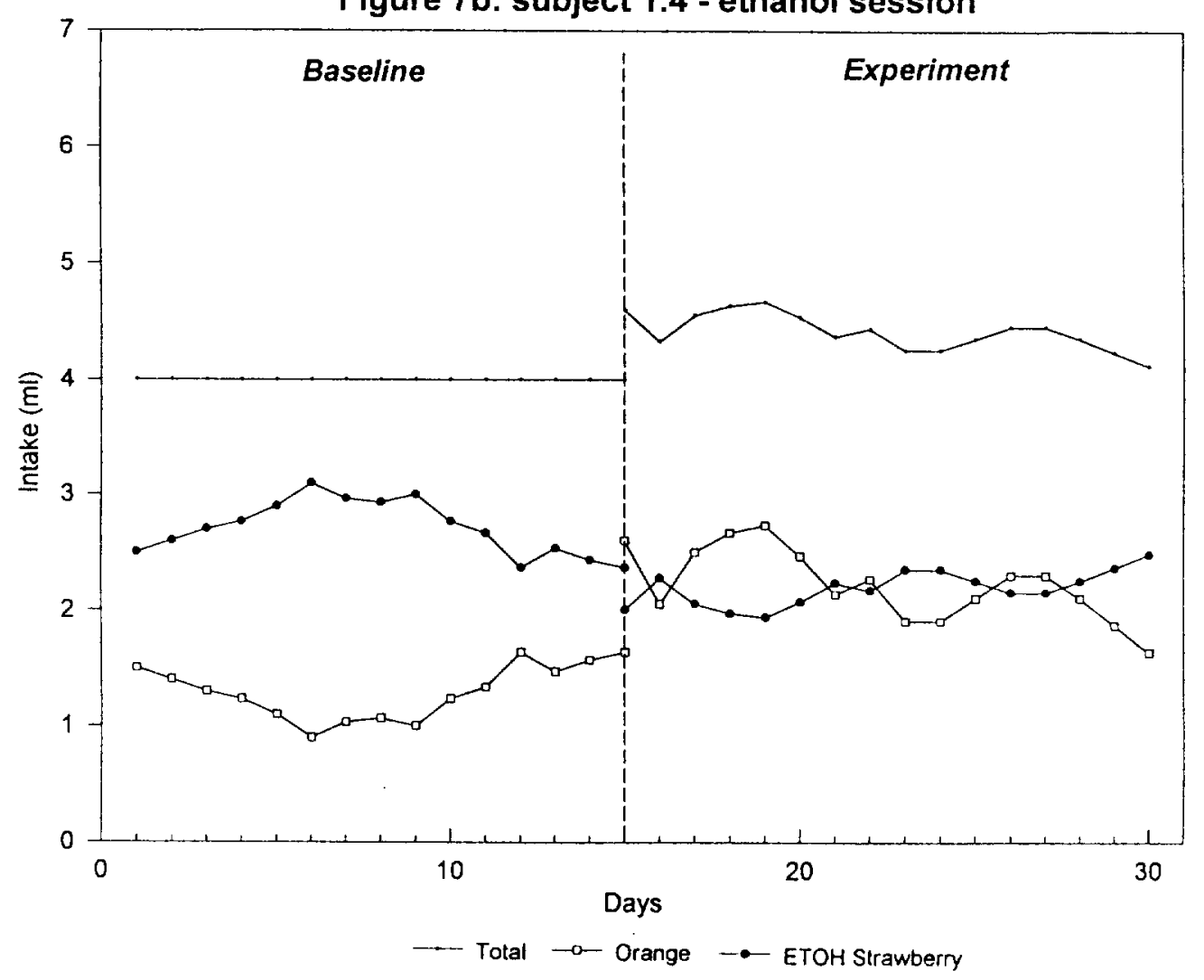


Figure 8a: subject 1.C1 - non-ethanol control

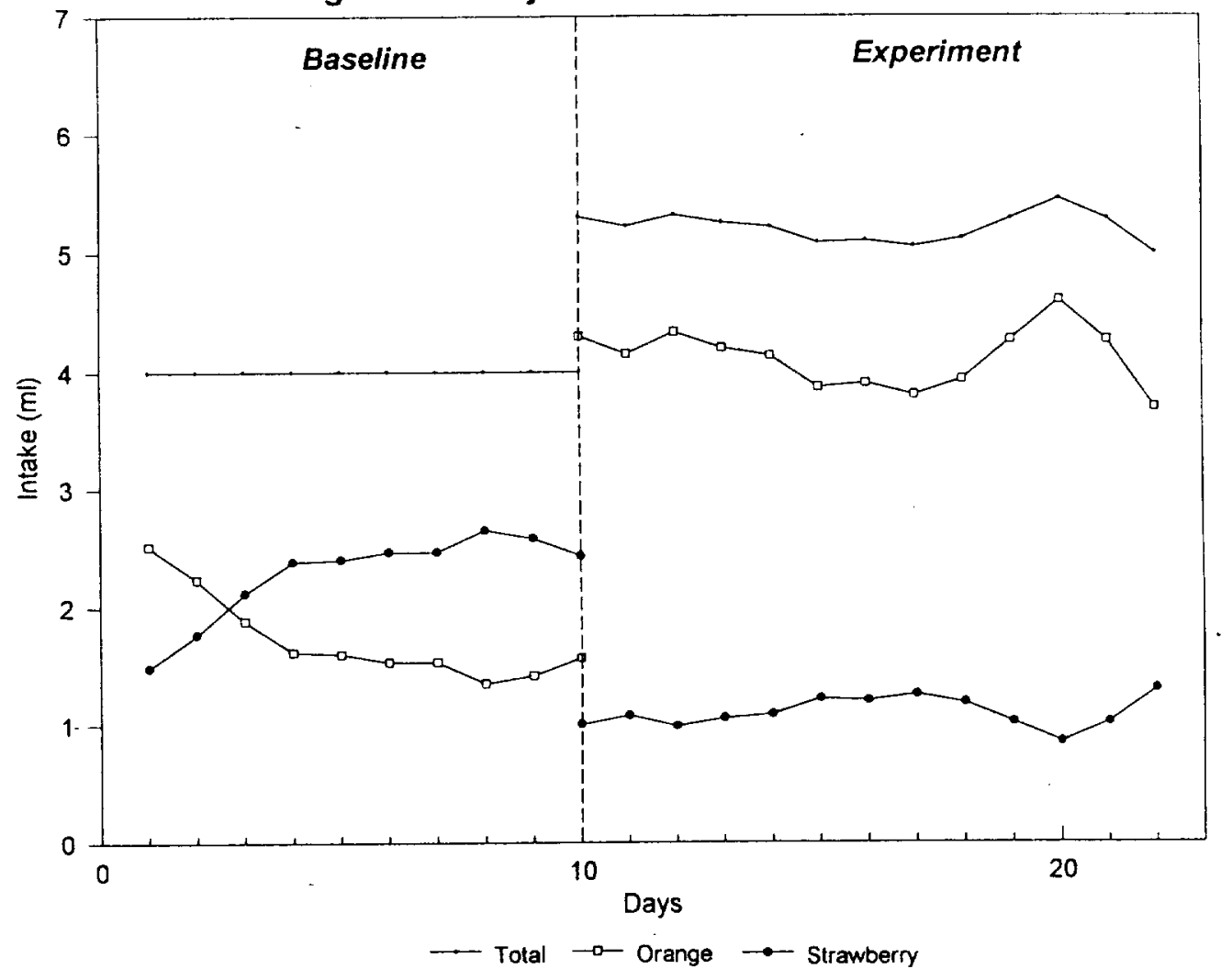

Figure $8 b$ : subject $1 . C 1$ - non-ethanol session

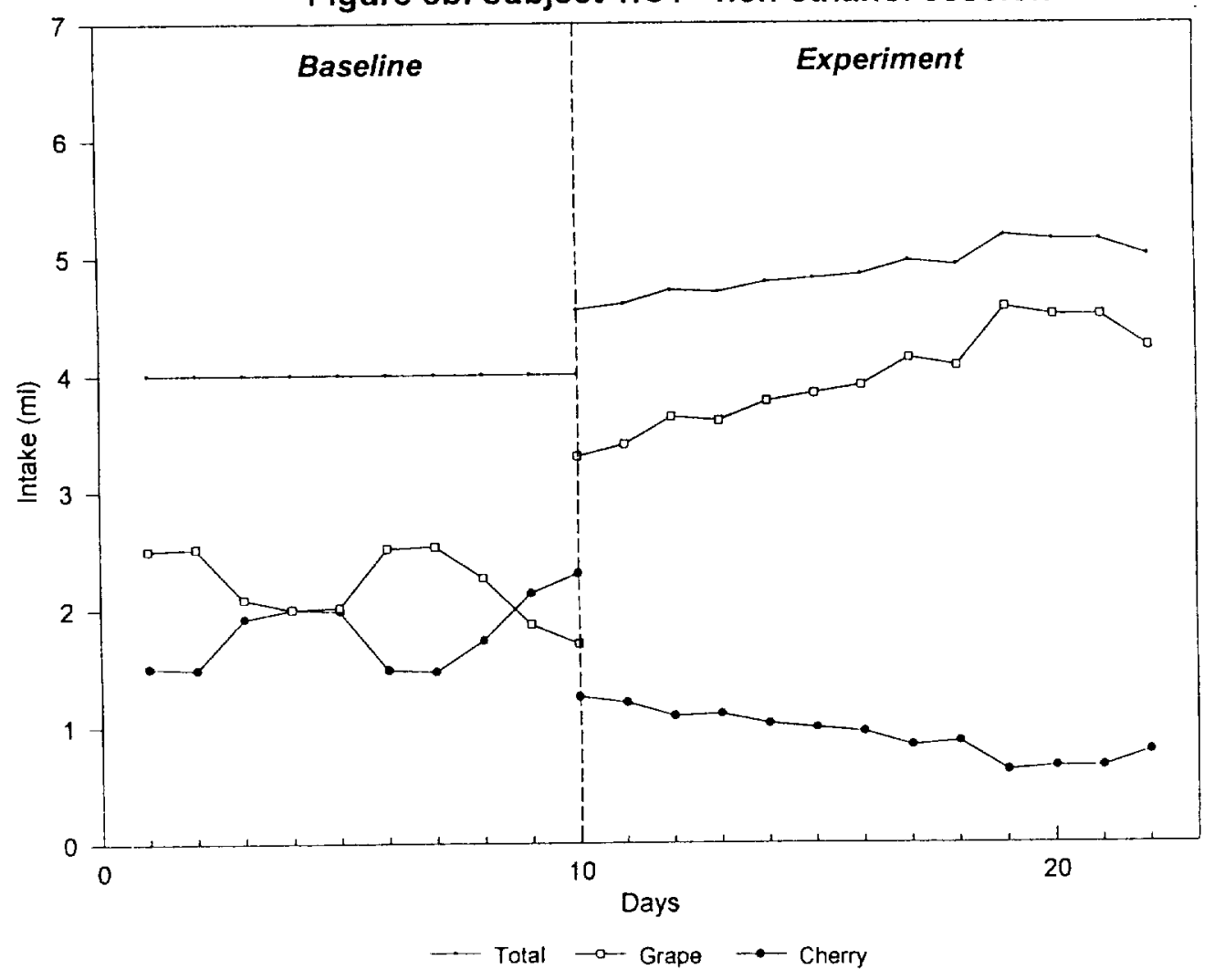


Figure 9: Home Cage vs. Operant Intake Subject 1.1

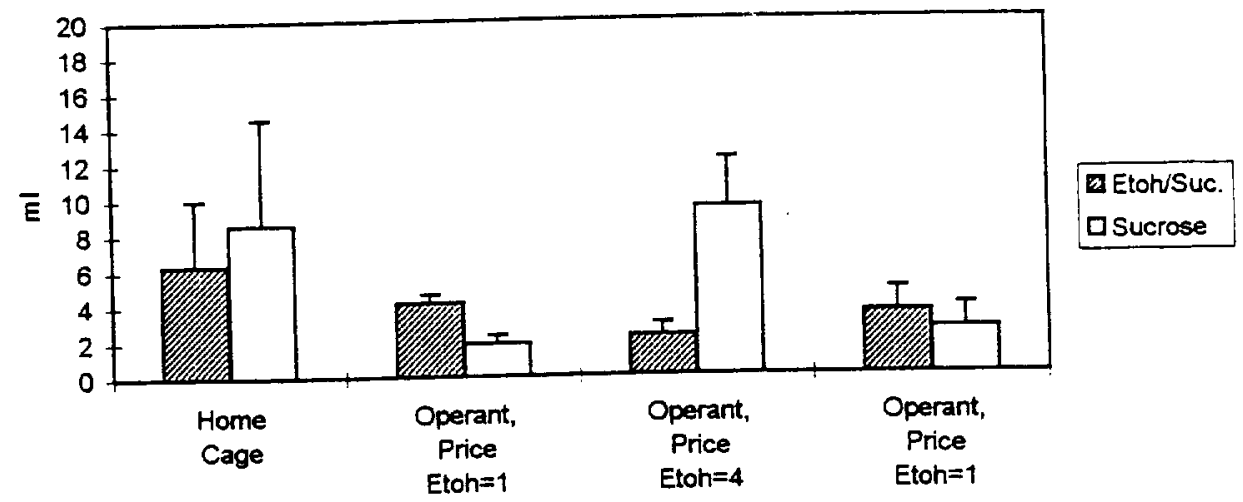

Figure 10: Home Cage vs. Operant Intake Subject 1.2

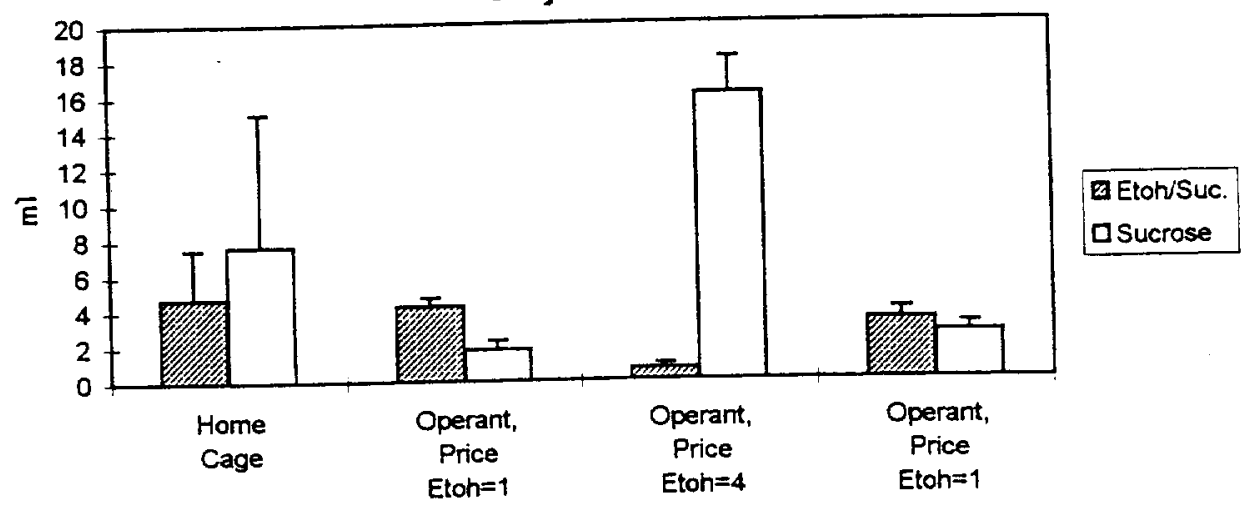

Figure 11: Home Cage vs. Operant Intake Subject 1.3

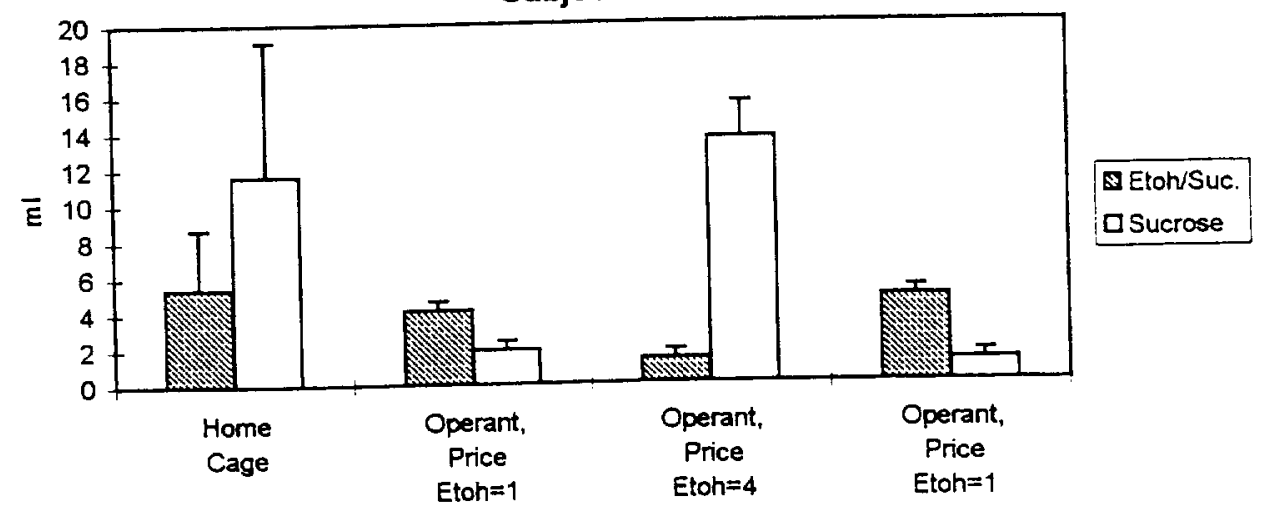

